\title{
PREDICTORS OF GROWTH AND DECLINE FOLLOWING SPIRITUAL STRUGGLES
}

\author{
Kavita M. Desai \\ A Thesis \\ Submitted to the Graduate College of Bowling Green \\ State University in partial fulfillment of \\ the requirements for the degree of
}

\section{MASTER OF ARTS}

May 2006

Committee:

Kenneth Pargament, Advisor

Anne Gordon

Annette Mahoney 


\begin{abstract}
Kenneth Pargament, Advisor

A number of studies have demonstrated links between spiritual struggles and a variety of growth and decline indices. As yet, however, no studies have investigated what determines whether struggles lead to growth and decline. The purpose of this current study was to help distinguish between these pathways. Based on literature on traumatic events, four potentially relevant categories were identified: struggle characteristics, religious history, support, and religious coping. Variables that captured each of these categories were identified and were tested as individual predictors of outcome following a spiritual struggle. Students from introductory psychology classes at a Midwestern university were screened to assess current spiritual struggle levels. Only those students that endorsed experiencing a spiritual struggle were eligible for the study. Participants completed a battery of questionnaires assessing for spiritual struggle, predictor variables, and outcome variables on-line. Four to six weeks after completing the first battery, participants were asked to complete a second battery, this one assessing outcome variables. A total of 127 participants completed measures at both time points. Results of the correlational analyses generally supported hypotheses. Five independent variables emerged as the strongest predictors of outcome from the regression equations. Specifically, religious purification coping, religious integration, and finding meaning from the struggle were significant predictors of growth, while avoidant attachment was a predictor of decline. Interestingly, struggle severity was a significant predictor of both
\end{abstract}


growth and decline, specifically secular growth and spiritual decline. The study

limitations and implications are discussed and suggestions for future research are identified. 
I would like to dedicate my thesis to my mom, dad, and sister. Thanks for all your support and encouragement throughout the years. 


\section{ACKNOWLEDGEMENTS}

First, I would like to express my gratitude to my advisor, Dr. Kenneth Pargament. When embarking on this journey, starting, let alone completing, a research project was a daunting task. You provided encouragement, acknowledging that research itself can be a “struggle”. Moreover, you created an atmosphere of independence and autonomy, allowing me to explore and learn from the research process, while offering support and guidance when needed. This experience, the completion of my master's thesis, has been my first attempt at an independent research project. With your guidance, support, and insight, this experience has become one of the cornerstones of my graduate training.

I would also like to thank the members of my committee, Dr. Anne Gordon and Dr. Annette Mahoney. Your insight and expertise helped me shape and develop my thesis to what it is today. More importantly, your critiques and feedback challenged me to strive for excellence. Your thoughtful comments on the manuscript and insightful questions during the meetings helped improve this project from the beginning. Your participation and support are greatly appreciated.

I give personal thanks to my family and friends who have endured the struggles that naturally ensued during this research project. First, to my family, your questions and interest about my degree progress and my research demonstrated your support, love, and investment in all the endeavors that I undertake. Your love and support have enabled me to branch off the traditional path, allowing me to follow my own inspiration and dreams. To all my friends, you have helped me endure the countless struggles along the way. You listened to my rants, quieted my fears, studied with me, taken much needed study breaks, and offered friendship during each leg of this journey. In particular, I would like to thank 
Nate Miller, who has listened, encouraged, and supported me throughout the entire process. Your understanding and support are greatly appreciated. Thanks to all of you, my advisor, committee, family, and friends; without you, this experience and project would not have been such a success. 


\section{TABLE OF CONTENTS}

Page

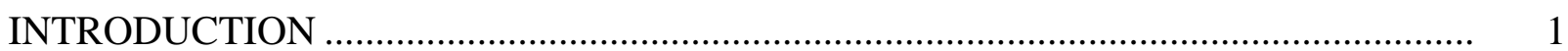

Defining Spiritual Struggles ..................................................................... 4

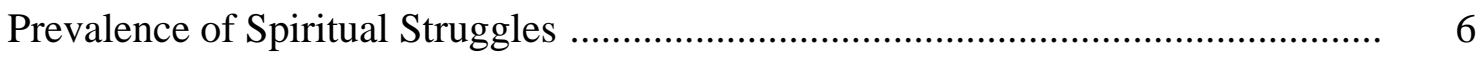

Literature Review of Spiritual Struggles ........................................................... 7

Potential Predictors of Growth and Decline ..................................................... 19

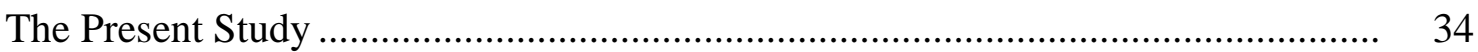

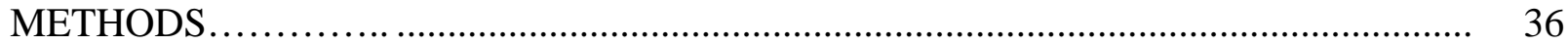

Sample Characteristics......................................................................... 36

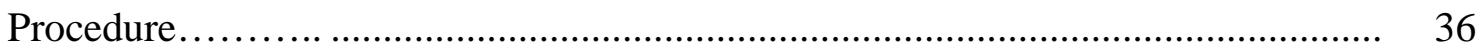

Spiritual Struggles Measures .................................................................. 39

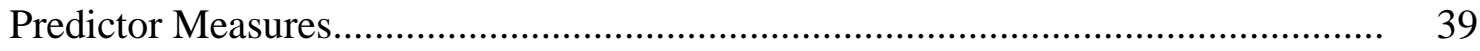

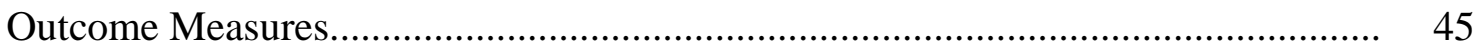

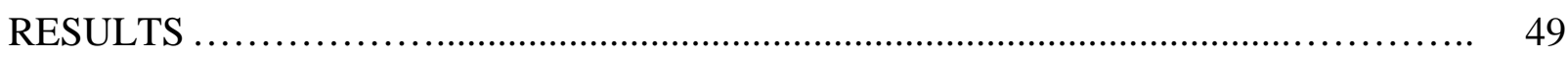

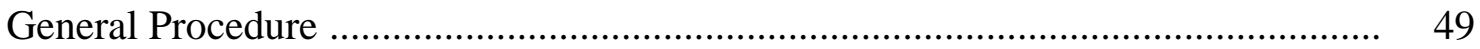

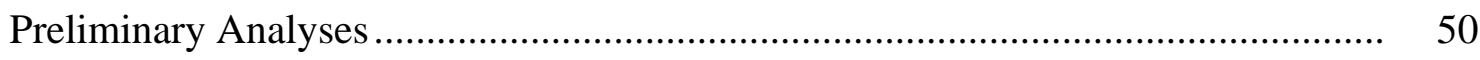

Correlational Analyses.......................................................................... 58

Hierarchical Multiple Regression Analyses................................................... 62

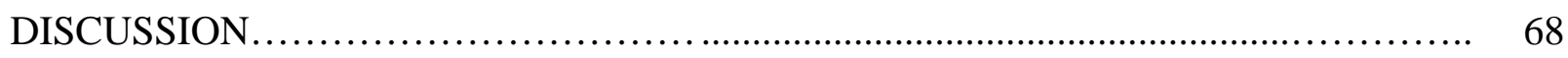

Correlational Findings ......................................................................... 69

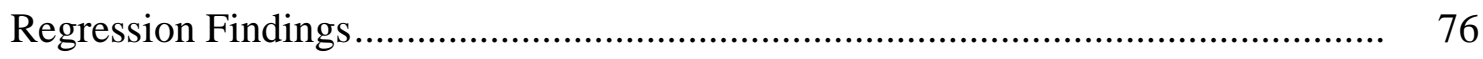

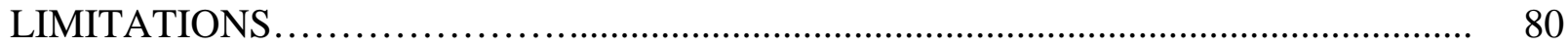


DIRECTIONS FOR FUTURE RESEARCH ...........................................................

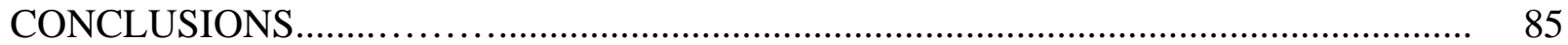

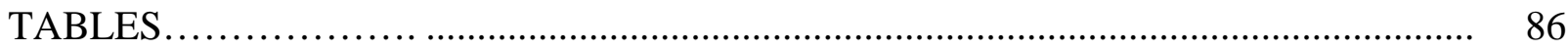

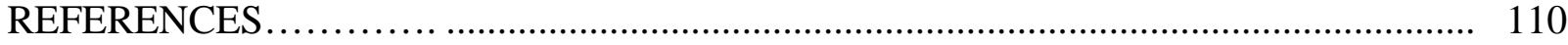

APPENDIX A. PREDICTOR MEASURES ........................................................... 118

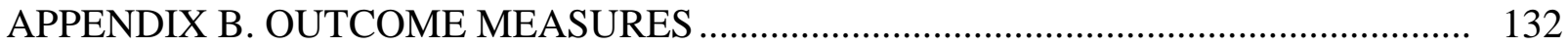




\section{INTRODUCTION}

Psychological research on religion has increased within the past few decades. Research has demonstrated links between spirituality, mental and physical health, and well-being. Additionally, individuals experiencing stressful events have been found to turn to their religious orientation system for psychological resources in the coping process (Pargament, 1997). The religious orientation system can be viewed as a “reservoir [that individuals] draw on during hard times” (Pargament, 1997, p. 100). Generally, the religious coping methods that grow out of the orienting system are effective in helping people cope with life stressors. However, the reservoir is not limitless. Stressful life events can overtax or strain the religious orienting system and lead to spiritual struggles. Spiritual struggles arise from an intersection between stressful life events and an individual's orientation system (Pargament, Murray-Swank, Magyar, \& Ano, 2005). They are a sign that the religious orienting system itself is under stress.

Spiritual struggles can cause distress and potentially harmful consequences for an individual. Krause, Ingersoll-Dayton, Ellison, and Wulff (1999) speculate that spiritual struggles can result in distress because they create cognitive dissonance for an individual. The authors suggest that spiritual struggles are "an unsettling state of indecision that arises from seeing the validity in two seemingly incompatible points of view,” (p. 526). For example, most religious traditions promise believers protection and security against harm. Psalm 38, verse 28 illustrates this: "For the Lord loves the just and will not forsake his faithful ones.” However, a traumatic event, such as an accidental death of a child, may leave believers feeling forsaken, therefore creating an inconsistency between expectations and actualities. This inconsistency may create cognitive dissonance for the 
individual and may cause considerable distress. Krause et al. suggest that the spiritual nature of the struggle may exacerbate the distress associated with cognitive dissonance. Since spiritual struggles involve matters that are sacred, these struggles are likely to be more threatening and painful than struggles outside the religious realm. Moreover, religious communities and scriptures may make individuals feel that experiencing a spiritual struggle is wrong, as illustrated by the verse "he who doubts is condemned" (Romans 14:23). Messages such as these may cause individuals to feel ashamed or guilty for struggling with their fundamental beliefs.

Although spiritual struggles have been linked to distress, they have also been viewed as a necessary ingredient to growth and development. From secular literature, developmental theorists have described struggles as a step towards growth. For example, Piaget (1985) believed that intellectual growth occurs as the result of disequilibria, or tension, between the old and the new; only when the individual is no longer able to assimilate new information into existing cognitive frameworks does he or she create new mental structures through cognitive accommodation. In his own words, “disequilibria alone force [the individual] to go beyond his current state and strike out in new directions,” (Piaget, 1985, p. 10). Similarly, religious theorists and psychologists studying religion have posited that struggles can lead to growth. Tillich (1957), a Protestant theologian, emphasized the relationship between doubting and faith, stating that "serious doubt is a confirmation of faith,” (p. 22). Moreover, Allport (1950) and Batson, Schroenade, and Ventis (1993) conceptualized mature and flexible religious beliefs as being open to questions and doubts. For example, Batson et al. (1993) discussed a mature, flexible approach to religion, the quest orientation. Individuals with quest 
orientation approach religion in a questioning manner, recognizing that although "he or she...probably never will know the final truth about [religious matters]...questions are [still] deemed important...” (p. 166).

Many religious traditions offer model figures that grew as a result of a spiritual struggle. For example, from the Judeo-Christian tradition, Moses is depicted as struggling spiritually several times within the book of Exodus. One specific instance is when he doubted God's decision to send him to rescue the Israelites from the Pharaoh of Egypt. Moses asked, "Who am I, that I should go to Pharaoh, and that I should bring forth the children of Israel out of Egypt?” (Exodus, 3:10).

The apostle Thomas, sometimes referred to as "Doubting Thomas," illustrates how other exemplary religious figures experience religious doubt. In John 20:25, Thomas stated that, "Unless I see the nail marks in his hands and put my finger where the nails were...I will not believe it." Jesus then appeared in front of Thomas, stating, "Put your finger here; see my hands. Reach out your hands and put it into my side. Stop doubting and believe,” (John, 20:27). From that point, Thomas became stronger in his faith, devoted the rest of his life to ministry, and became a martyr.

Religious figures in the midst of spiritual struggles also appear in Eastern religions, such as Hinduism and Buddhism. For example, the focus of the Bhagavad-Gita, a Hindu scripture, is Arjuna's internal struggle with his Godly duty to serve as a warrior for the Pandavas, who represented morality and justice, against the Kauravas, who represented greed and dishonesty. Arjuna questioned his duty as a warrior and turned to his charioteer, Lord Krishna (a divine incarnation of God) for advice. Through conversations with Krishna, Arjuna becomes enlightened, saying, "Krishna, I see the 
truth now, by your immeasurable kindness. I have no more doubts,” (Bhagavad-Gita, 18:73).

Buddha is another example of a religious figure who undergoes a spiritual struggle. In the process of becoming enlightened, Buddha experienced several challenges. Mara, the evil one, tempted Buddha with the promise of nirvana: "Who could be expected to understand truth as profound as that which the Buddha had laid hold of...Why bother to play the idiot before an uncomprehending audience? Why not wash one's hands of the whole hot world-be done with the body and slip at once into nirvana...the argument was so persuasive that it almost carried the day. At length, however the Buddha answered, 'There will be some who will understand,' and Mara was banished from his life forever” (Smith, 1991, p. 87). Based on these examples from various religions and secular and religious theorists, it seems that spiritual struggles can lead to growth and development.

Spiritual struggles, then, may represent a fork along the spiritual pathway. [Instead of metaphor of a double-edged sword] Theoretically, spiritual struggle could lead to growth and/or decline. Similarly, research on spiritual struggles has provided some support for the possibilities of both outcomes. What determines whether struggles will lead to growth or decline? The factors leading to these different outcomes have not yet been established. This study will attempt to identify and distinguish between the pathways leading to growth and decline.

\section{Defining Spiritual Struggles}

Spiritual struggles develop from an intersection between stressful life experiences and an individual's personal orientation system (Pargament, Murray-Swank, \& Ano, 
2005). "Stressful life experiences” encompasses a variety of potential stressors. For example, a single unexpected event, such as a car accident or the loss of a loved one, may overtax the orientation system and trigger a spiritual struggle. Conversely, a stressful life experience may reflect the cumulative effect of normative developmental processes and transitions. For example, leaving home and starting college may be one normative life experience that triggers a spiritual struggle. Spiritual struggles refer to expressions of conflict, question, doubt, and tension about matters of faith, God, and religious relationships. Spiritual struggles can be understood as coping efforts to conserve or transform a spirituality that has been threatened or harmed. What differentiates spiritual struggles from other spiritual coping processes is the expression of spiritual stress, strain, or distress within the coping process.

Spiritual struggles can be subdivided into three categories: interpersonal, intrapsychic, and divine. Interpersonal spiritual struggles consist of conflict, tension, and strain within religious relationships, be it family, friends, or congregation members. Intrapsychic spiritual struggles reflect internal turmoil, including doubts, questions, and uncertainty, regarding religious matters. Doubting the veracity of religious scripture and questioning God's existence are examples of intrapsychic struggles. Lastly, divine spiritual struggles reflect conflict in one's personal relationship with the divine. Anger at God, turning away from God, fearing God, and beliefs that the devil caused a negative event are all ways that the relationship between an individual and God may be strained. Interpersonal spiritual struggles can be distinguished from intrapersonal and divine spiritual struggles. Specifically, intrapsychic and divine struggles reflect a personal tension about one's religious beliefs, whereas interpersonal struggles reflect a tension 
between the individual and others, be it a single individual or a congregation. Because interpersonal spiritual struggles are conceptually different from intrapsychic and divine struggles, this study focused on the latter types of struggles.

\section{Prevalence of Spiritual Struggles}

Spiritual struggles are relatively commonplace, with most individuals experiencing them at some point during their lifetime. For example, a recent survey of undergraduate students $(n=5,472)$ from 39 public and private colleges and universities found that $44 \%$ endorsed current distress caused by "spiritual/religious” concerns (Johnson \& Hayes, 2003). After dividing the sample into two groups, the researchers found that $32 \%$ of students seeking services from counseling centers and $57 \%$ of those not seeking services, were at least "a little bit” concerned with religious/spiritual problems. These findings suggest that roughly half of a college sample, at any given time, may experience at least “a little bit” of distress caused by religious/spiritual issues.

Specific research on religious doubts and anger towards God demonstrates that these forms of spiritual struggle are also commonplace. For example, 78\% of seniors from parochial schools reported that they were currently experiencing religious doubt and $12 \%$ reported that they had doubted in the past. In fact, only $9 \%$ reported never experiencing religious doubt (Kooistra \& Pargament, 1999). Anger at God has also been found to be a common experience: $63 \%$ of adults from a probability sample in the United States (data from the 1988 General Social Survey) indicated sometimes experiencing anger towards God (Exline, 2003). Moreover, one-third of men sampled from homeless shelters reported that becoming homeless elicited negative feelings in their personal relationship with God (Exline, 2003). 
Although research on spiritual struggles is limited, this area of study has been receiving more attention. In fact, the newest edition of the Diagnostic and Statistical Manual includes "religious or spiritual problems" as a factor that "may be a focus of clinical attention,” (American Psychological Association, 2000, p. 685). Additionally, spiritual struggles are experienced across a variety of samples. Studies have shown that adults (e.g., Nielson, 1998), high school students (e.g., Hunsberger, Pratt, \& Prancer, 2002; Kooistra \& Pargament, 1999), hospital patients (e.g., Pargament, Koenig, Tarakeshwar, \& Hahn, 2001; Fitchett, Rybarczyk, DeMarco, \& Nicholas, 1999), and even religious leaders (e.g., Pargament, Tarakeshwar, Ellison, \& Wulff, 2001; Krause, Ellison, \& Wulff, 1998) experience spiritual struggles.

\section{Literature Review of Spiritual Struggles}

Although the construct "spiritual struggle" is relatively new, researchers have been investigating related ideas for several years. These researchers have focused on specific types of spiritual struggles, often labeling them differently, such as religious doubting (e.g., Krause, Ingersoll-Dayton, Ellison, \& Wulff, 1999), religious guilt (e.g., Exline, Yali, Sanderson, 2000), and anger at God (Pargament, Koenig, Tarakeshwar, \& Hahn, 2001). Additionally, these concepts were assessed with a range of instruments, including the Negative Religious Coping scale (e.g., Pargament, Magyar, Benore, \& Mahoney, 2005), Religious Strain Scale (e.g., Exline, Yali, \& Sanderson, 2000), and Uncertainty and Doubting scales (Kooistra \& Pargament, 1999). Irrespective of these differences, conceptually these studies investigated types of spiritual struggle and consequently form the foundation for this new concept. Therefore, to clarify the various 
patterns of findings, the existing literature will be reviewed and be classified as an intrapsychic or divine spiritual struggle based on the definitions used in this study. Intrapsychic Spiritual Struggles.

Intrapsychic struggles have been studied in college, clinical, and religious samples. Although only a few studies have looked specifically at this type of struggle, findings suggest that intrapsychic struggles are generally related to negative outcomes. Relevant articles will be subdivided based on the research design, cross-sectional or longitudinal.

Cross-sectional studies. Studies investigating intrapsychic spiritual struggles have demonstrated links between struggle and indices of distress. For example, Exline, Yali, and Sanderson (2000) investigated intrapsychic spiritual struggles in clinical and college samples, using the Religious Strain Scale. This scale included three subscales: religious rifts, alienation from God, and religious fear/guilt. The last subscale can be classified as an intrapersonal struggle because it reflects internal religious conflict. Exline et al. found that religious fear and guilt were significantly correlated with an increased risk of suicide $(r=.30, p<.05)$ in the clinical population. Suicidality was not measured in the undergraduate sample. Interestingly, they did not find any significant correlations between religious fear and guilt with depression in either sample.

Significant correlations between intrapsychic struggles and decline outcomes have also been found in studies that focus on religious samples. Krause, Ingersoll-Dayton, Ellison, and Wulff (1999) investigated elders and rank-and-file members from the Presbyterian Church USA. Based on regression analysis, they found that religious doubting "eroded" feelings of well being for all individuals ( $\beta=.20, p<.001)$. 
Additionally, there was an interaction between age, religious doubting, and well-being: religious doubting affected younger members more than older ones $(\beta=.37, p<.001$ for 20 year olds; $\beta=.32, p<.001$ for 40 year olds; and $\beta=.17, p<.001$ for 60 year olds). In fact, by age 80, religious doubting was not found to have any deleterious effects on wellbeing $(\beta=.072, p>.05)$. The authors speculated that older members coped better with religious doubts, thus reducing the negative impact of doubts on well-being. Another study focused on congregation members from a Roman Catholic Church and an undergraduate population (Pargament, Zinnbauer, Scott, Butter, Zerowin, \& Stanik, 1998). For church members, religious doubt was correlated with decreased self-esteem ( $r$ $=-.65, p<.001)$ and general psychological outcomes $(r=-.49, p<.001)$, and with increased anxiety $(r=.68, p<.001)$ and negative mood $(r=.42, p<.001)$. For undergraduate students, religious doubts were tied to poorer general outcomes $(r=-.29, p$ $<.001)$, religious outcomes $(r=-.43, p<.001)$, and more negative mood $(r=.47, p<$ .001). These findings indicate that spiritual struggle was related to significant harm psychologically and religiously. Of the studies reviewed, this was the first to include religious variables as an outcome measure.

Kooistra and Pargament (1999) investigated intrapsychic struggles in a younger religious sample, students in Protestant and Roman Catholic parochial high schools. Specifically, they looked at religious doubting among these students. Intrapsychic struggles were assessed by the Uncertainty and the Wondering scales (Kooistra \& Pargment, 2001). For Protestant students, endorsement of both scales was related to increased anxiety (correlations ranging from .36 to .37, $p<.001$ ) and negative affect (correlations ranging from .30 to .32, $p<.001$ ). However, for Catholic students, only the 
Wondering scale was related to these outcomes (for negative affect, $r=.26, p<.01$; for anxiety, $r=.33, p<.001)$. Kooistra and Pargament speculated that the Uncertainty scale was related to outcomes for Protestants but not Catholics because religion was more important to Protestant students. Specifically, Protestant students endorsed higher intrinsic religiosity than Catholic students, indicating that their religious beliefs were more integrated into their lives. Since religious beliefs were more central to the Protestant students, the experience of doubts may have caused more distress.

Ryan, Rigby, and King (1993) investigated religious motivation and its relationship to mental health in four different religious samples. They found that introjection, defined as partial or superficial internalization of religious beliefs, was related to negative physical health ( $r$ ranged from .16 to .20, $p<.05)$ and self-esteem $(r$ ranged from -.22 to -.27, $p<.01$ ). Introjection can be viewed as an intrapersonal spiritual struggle because it reflects religious beliefs and values that have not been incorporated into one’s life; implying internal tension regarding religious beliefs. Internalization, in contrast to introjection, reflects a more fully realized integration of religious beliefs and was correlated with better general health and self-esteem (correlations ranged from .21 to $.36, p<.05)$.

Longitudinal studies. Only a few studies have investigated the longitudinal implications of intrapsychic spiritual struggles. For example, Hunsberger, Pratt, and Prancer (2002) investigated religious doubting in high school students and conducted a 2year follow-up of these students. Their initial sample consisted of 939 high school students from various public and private schools and their follow-up sample consisted of 336 students. Although the attrition rate was relatively high (62\%), the authors found that 
the follow-up participants did not differ significantly on any measure from those that dropped out. At time one, the researchers found that students' religious doubts significantly correlated with negative psychological outcomes, specifically to lower dispositional optimism $(r=-.12, p<.05)$ and increased depression $(r=.12, p<.05)$. The students' doubt levels remained relatively stable over the two years. However, at followup, doubting was not significantly correlated with psychological variables. Although doubting levels remained the same, it seems that the adverse impact of doubting diminished over time. Hunsberger et al. also investigated denominational differences because of the findings from the Kooistra and Pargament (1999) study. The findings by Hunsberger et al. differed from those of Kooistra and Pargament. They found that the relationship between doubt and negative outcomes was stronger for mainstream students than religiously fundamental ones. The authors attributed this inconsistency to the differences in the samples. The sample used by Hunsberger et al. was more diverse than the sample in the Kooistra and Pargament study. Despite the disparity in the findings related to denominations, both studies indicated that intrapersonal spiritual struggles are associated with negative psychological outcomes, at least initially.

Fitchett, Rybarczyk, DeMarco, and Nicolas (1999) also investigated the longitudinal impact of intrapersonal struggles. Their study focused on individuals experiencing a significant stressful event, hospitalization in an inpatient medical rehabilitation unit. The researchers surveyed patients within a few days (up to four) after being admitted and at four months after discharge. At admission, religious guilt and disbelief, measured by the Spiritual Injury Scale, was associated with greater depression $(r=.48, p<.01)$ and lower life satisfaction $(r=-.33, p<.01)$. However, this scale was no 
longer tied to the criteria after controlling for baseline levels of physical functioning, general health, and other covariates.

Taken together, these studies demonstrate significant relationships between intrapersonal spiritual struggles and physical, psychological, and religious indicators of health and well-being. In each of these studies, intrapsychic struggle had consistent patterns of findings. Overall, when looking at results from cross-sectional analysis, intrapsychic struggles are consistently related to poorer outcomes. However, based on longitudinal analyses, the adverse impacts of the struggle appear to decline over time. These are tentative conclusions based on two longitudinal studies. The pattern of findings for studies that investigated divine struggles is less straightforward. Divine Struggles.

Divine struggles have received more empirical attention than intrapsychic struggles, with more complicated results. Below the studies on divine struggles are subdivided based on the methodology used (either cross-sectional or longitudinal studies).

Cross-Sectional Studies. Pargament, Magyar, Benore, and Mahoney (2005) assessed divine struggles in a community sample. The researchers asked participants (125 individuals) to identify the most negative life event that they had experienced within the past two years. The participants then filled out a battery of questionnaires assessing perceptions of the event as a spiritual violation (i.e.,, desecration), their ways of religious coping with the event, and the outcomes of the event. This study assessed spiritual struggles using the Negative Religious Coping scale (NRCOPE). This scale consists of items such as “wondering whether God has abandoned me” and "feeling punished by 
God for my lack of devotion.” The authors found that negative religious coping acted as a partial mediator of the relationships between desecration and outcomes. Furthermore, negative religious coping was related to greater traumatic impact, emotional distress, and poorer physical health (correlations ranged from .34 to .60, $p<.01$ ). The authors concluded that negative religious coping seems to be one of the mechanisms by which negative spiritual appraisals relate to health outcomes.

Other studies have investigated divine struggles in response to specific stressors. One such study surveyed family members who had experienced an unexpected death of a loved one due to homicide (Thompson \& Vardman, 1997). The family members that were surveyed were mainly female (86\%) and African American (90\%). The researchers found that divine struggles, specifically religious discontent, were correlated with higher levels of posttraumatic stress $(r=.43, p<.001)$ and distress $(r=.28, p<.001)$.

Belavich and Pargament (2002) studied divine struggles in response to a different stressor: waiting for a loved one undergoing surgery. For this study, individuals were asked to fill out a survey while waiting for a loved one in surgery. Belavich and Pargament (2002) found that loved ones who reported greater religious discontent, assessed using the Religious Coping Activities Scale, also expressed more distress.

In a between-groups analysis, Trenholm, Trent, and Comptom (1998) compared three groups: females in a panic disorder support group, clients in psychotherapy for disorders other than panic, and community members. They found that the panic support group endorsed significantly greater amounts of spiritual struggle (measured by the Survey of Attitudes Towards Religion and Philosophy of Life scale) than the other two groups $(\mathrm{F}(2,57)=6.77, p<.01)$. Moreover, struggle discriminated significantly between 
the panic support group and the therapy group and between the panic support group and the community sample.

Thus far, the review of articles on divine struggles has focused on secular samples. Some studies have investigated the impact that divine spiritual struggles have on religious samples. In one such study, members of 10 Christian churches in the Midwest were asked to describe how they coped with their most serious negative event in the past year (Pargament, Ensing, Falgout, et al., 1990). Divine struggles, measured by the Religious Coping Activities Scale, were predictive of poorer general health $(r=-.22, p<$ $.001)$ and religious outcomes $(r=-.12, p<.001)$.

Pargament, Tarakeswhar, Elision, and Wulff (2001) studied a sample of clergy, elders, and members from the Presbyterian Church, USA. This study utilized the Negative Religious Coping scale to assess for divine struggles. Although the endorsement of divine struggles was low for all three groups, clergy and members endorsed the same amounts of divine struggles, whereas elders endorsed a significantly smaller amount. In each of the three groups, divine struggles were associated with decreased positive affect ( $r$ ranged from -.33 to -.68, $p<.01$ ) and increased depressive affect (correlations ranged from .52 to $.59, p<.01)$. These associations were stronger for clergy and elders than for members. Moreover, struggles were correlated with less religious satisfaction for clergy $(r=-.075, p<.01)$ and elders $(r=-.056, p<.05)$, but not for members. Further, this effect was stronger for clergy than for elders. Thus, although divine struggles were tied to negative affect for individuals of all ranks in the Presbyterian Church, the effects were stronger for people more centrally involved in the church. 
Pargament, Zinnbauer, Scott, Butter et al. (1998) examined negative religious coping in religious, Catholic Church, and secular, university, samples. In the undergraduate student sample, two specific stressors were assessed: the experience of a personal injustice and the death of a family member or friend. Participants in the Catholic sample were asked to recall the most negative life event experienced within the past year. For each of these samples, struggles were associated with increased anxiety and negative mood, and decreased self-esteem (correlations ranged from .25 to .62, $p<.05$ ). Moreover, for students who had experienced the death of a loved one and Catholic Church members, struggles were linked to decreased "general outcomes” (defined as general benefits subsequent to the resolution of the event), and "religious outcomes" (defined as religious benefits subsequent to the resolution of the event (correlations ranged from -.20 to $-.57, \mathrm{p}<.05)$.

A few studies on divine struggles have expanded the focus of investigation to include a growth outcome measure. For example, Koenig, Pargament, and Nielson (1998) studied the impact of divine struggles (measured by the Negative Religious Coping scale) on depression, quality of life, stress-related growth, cooperation, and spiritual growth in an elderly medically ill sample. Focusing on the subscales of the Negative Religious Coping scale indicative of divine struggles (i.e., Punishing Reappraisals, Demonic Reappraisals, Reappraisal of God's power, and Spiritual Discontent), divine struggles were consistently tied to higher levels of depression (correlations ranged from .15 to .25, $p<.01$ ) and lower quality of life (correlations ranged from -.10 to $-.19, p<.01$ ). Divine struggles were inconsistently tied to growth measures (stress-related growth and spiritual growth). Specifically, Punishing God Appraisals, and Demonic Reappraisals were 
associated with higher levels of stress-related growth $(r=.14$ and .17 , respectively, $p<$ .01). In contrast, Reappraisals of God’s Power was related to lower reports of stressrelated growth $(r=-.09, p<.05)$. With respect to spiritual growth, Demonic Reappraisals were linked to report of greater spiritual growth $(r=.20, p<.001)$ and Reappraisals of God's Power were associated with lower levels of spiritual growth $(r=-.24, p<.001)$. More consistent findings were reported by Pargament, Koenig, and Perez (2000). Their study assessed elderly medical patients and undergraduate students coping with medical illness and a range of other life stressors. They found that specific subscales of Negative Religious Coping, Demonic and Punishing Reappraisals, Spiritual Discontent, and Reappraisals of God's Power, were all related to higher levels of stress-related growth and spiritual growth (correlations ranged from .12 to .20, $p<.05$ ). Interestingly, these same indices were also related to higher levels of distress and poorer mental health outcomes (correlations ranged from .08 to .19, $p<.01$ ). Thus, spiritual struggles, measured by the Negative Religious Coping scale, appeared to be linked to both higher levels of growth and higher levels of distress.

This pattern of findings was also demonstrated in a study by Pargament, Smith, Koenig, and Perez (1998). They assessed divine struggles using the Negative Religious Coping scale in three samples: elderly hospital patients, church members surrounding the Oklahoma City bombing area, and undergraduate students. In the hospitalized sample, struggles were related to negative health and psychological outcomes, such as quality of life and depression (correlations ranged from .15 to .31, $p<.01$ ). In response to the Oklahoma City bombing, divine struggles by church members were correlated with increased posttraumatic stress symptoms and callousness $(r=.39$ and $.36, p<.001$, 
respectively). For college students coping with a recent negative life event, struggles were related to higher levels of current distress and poorer physical health $(r=.18$ and $.13, p<.01$, respectively). However, in all of these samples, divine struggles were tied to measures of growth (correlations ranged from .12 to $.38, p<.01$ ).

Longitudinal. There have been a few studies investigating the long-term effects of divine struggles. For example, Fitchett, Rybarczyk, DeMarco, and Nicholas (1999) studied patients in medical rehabilitation and found that divine struggles (measured by Negative Religious Coping scale) at the time of admission to a rehabilitation unit were correlated with increased depression $(r=.21, p<.05)$. Moreover, after four months, Negative Religious Coping predicted a decline in somatic autonomy, even after controlling for other variables. Specifically, "anger at God” was predictive of somatic decline. This item accounted for $9 \%$ of variance, in contrast to the full scale, which accounted for $5 \%$ of variance. Fitchett et al. concluded that forms of negative religious coping compromised recovery in medical rehabilitation patients, more so than other variables, such as demographics, social support, and independent activity level upon admission.

Another longitudinal study of hospital inpatients patients, ages 55 and older, further supports the notion that divine struggles may have long lasting adverse effects (Pargament, Koenig, Tarakeshwar, \& Hahn, 2001). The researchers compared spiritual struggle levels (assessed by the Negative Religious Coping scale) at baseline with patient's status after 2 years. The authors subdivided the sample based on their health status after two years. Specifically, the authors were interested in differences between the individuals that were alive at the follow-up and those that had passed away. At baseline 
hospital evaluation, both groups endorsed low levels of divine struggles. However, individuals that were alive at time two had reported significantly lower amounts of spiritual struggles at baseline than those that passed away $(M=3.1$ for baseline spiritual struggles for the deceased group, $M=2.3$ for baseline spiritual struggles for the alive group). The authors found that struggles were better predictors of mortality than were other typical "long life” variables such as race, diagnosis, cognitive functioning, depressed mood, quality of life, and independence in daily activities. Moreover, they were able to identify three specific items that were more predictive of mortality: alienation by God, feelings of not being loved by God, and attributing the illness to the devil. These items were associated with between $19 \%$ to $28 \%$ increase in mortality rates.

Smith, Pargament, Brant, and Oliver (2000) studied the long-term implications of divine struggles (assessed by the Religious Coping Activities Scale) in a religious sample. The researchers surveyed church members (75\% Protestant and 25\% Catholic) affected by the 1993 Midwest floods. The members were surveyed 6 weeks post-flood and again 6 months later. At time one, divine struggles were significantly correlated with psychological distress $(r=-.24, p<.01)$. Struggles were significantly related to spiritual decline at both times ( $r=.18$ and $.20, p<.05$, respectively). These findings point to the potentially long-term implications of divine struggles.

In summary, it seems that divine struggles can be associated with both growth and decline. Specifically, cross-sectional studies demonstrated inconsistent findings, with struggles related to both growth and decline; whereas longitudinal studies demonstrate the negative impacts of divine struggles and how these struggles may impact well-being over time. It is interesting to note that divine struggles have negative impacts 
longitudinally, whereas studies on intrapsychic struggles suggest a more time-limited impact. This is an interesting pattern of results; however, interpretation of this is tentative because only two studies investigated the longitudinal impacts of intrapsychic struggles. The literature reviewed above was subdivided into intrapsychic and divine struggles to clarify the patterns of findings for each type of struggle. However, since the literature on spiritual struggles is relatively new and since the relationship between these struggle types have not been identified, for the purpose of this study, intrapsychic and divine spiritual struggles will be treated as a single construct, spiritual struggles.

Overall, these studies suggest that spiritual struggles may in fact be a fork in the spiritual pathway. As demonstrated above, struggles have been tied to a variety of poorer physical, mental, psychological, and religious outcomes. However, in a few studies, spiritual struggles have also been correlated with positive outcomes, such as stress related growth and spiritual growth. What determines whether spiritual struggles are linked to growth or decline? Below several potential predictors of the consequences of spiritual struggles are described.

\section{Potential Predictors of Growth and Decline}

\section{Struggle Characteristics:}

Intuitively, it seems logical to assume that various characteristics of the spiritual struggle should influence its consequences. Empirical evidence from the literature on secular and spiritual struggles points to two characteristics that may impact the aftermath of a struggle: severity of the struggle and the ability to find meaning from the struggle.

Struggle Severity. Research has demonstrated links between severity of an event and growth. People seem to experience greater growth from more severe events. For 
example, in a study of middle and older aged adults (ages 45 and older) suffering from recent vision loss, individuals that reportedly experienced higher levels of adversity in their lives also reported greater psychosocial development $(r=.17, p<.05)$ as measured by the Inventory of Psychosocial Balance (Brennan, 2002).

Although there seems to be a positive relationship between event severity and growth, some evidence suggests that this relationship follows a curvilinear pattern, with the most growth following an intermediate amount of trauma as opposed to either extreme. Results from the National Vietnam Veterans Readjustment Study, in which 1,198 males who fought in Vietnam and the surrounding area were surveyed, provides support for a curvilinear relationship between growth and trauma exposure (Fontana \& Rosencheck, 1998). Five specific traumatic events that could be experienced in a war zone were identified and assessed: fighting, killing others, perceived threat to self, death/injury to others, and atrocities. Through coding and analyzing essays about the positive and negative "things" that veterans gained from their war experience, three general categories of psychological benefits were identified: affirmation of patriotic themes (endorsed by 10\%), self-improvement (47\%), and solidarity with others (17\%). For most trauma types, a curvilinear relationship was found between the amount of trauma exposure and psychological benefits. Generally, this relationship followed an “inverted U” shape, such that more benefits were experienced for intermediate traumas, with the two extremes experiencing lower amounts of benefits.

The curvilinear relationship between event severity and growth seems counterintuitive. One possible explanation for these findings is that events of greater severity shatter a person's worldview (Janoff-Bulman, 1992) leaving more room for 
growth. A negative life event that leaves the worldview relatively unscathed does not offer the same growth potential.

Currently, research has not investigated the relationship between the initial stressfulness of spiritual struggles and outcome. However, to the extent that spiritual struggles can be likened to traumatic events, the above findings suggest that initial stressfulness of a spiritual struggle may be positively related to growth. It is hypothesized that struggle severity will predict growth outcomes.

Meaning. Another potentially important factor for predicting growth and decline is the ability to extract meaning from the spiritual struggle. In the secular literature, the ability to find meaning from a negative event has been linked to psychological adjustment, well being, and fewer depressive symptoms. A study investigating psychological adjustment in stroke patients and their caregivers provides one example (Thompson, 1991). Results from this study indicated that stroke patients (50\%) and their caregivers (45\%) were able to find meaning from the stroke. Being able to find meaning was related to better psychological adjustment, specifically fewer depressive symptoms and feelings of enhanced purpose in life, for both patients and caregivers $(r=.50, p<.01$; $r=.29, p<.05)$.

Farber, Mirsalimi, Williams, and McDaniel (2003) also demonstrated the positive ties between finding meaning and psychological adjustment for individuals with symptomatic HIV and AIDS. Finding meaning from HIV/AIDS was related to increased psychological well-being $(r=.50, p=.01)$ and decreased depression $(r=-.49, p=.01)$. Moreover, the ability to find meaning added unique predictive power above and beyond the effects of coping style and social support. Specifically, ability to find meaning 
predicted $15 \%$ of unique variance in psychological well-being $\left(\Delta \mathrm{R}^{2}=.15, \beta=.41, \mathrm{p}\right.$ $<.001)$ and $16 \%$ of unique variance in depression $\left(\Delta \mathrm{R}^{2}=.16, \beta=-.42, \mathrm{p}<.001\right)$.

Being able to find meaning in the death of a child was also related to benefits for parents over time (Murphy, Johnson, \& Lohan, 2003). In a longitudinal study, 57\% of parents that had lost a child due to homicide, suicide, or accident were able to find some meaning from this traumatic event. Moreover, this ability to find meaning was related to lower mental distress, increased marital satisfaction, and better physical functioning.

Individuals assume the world is a meaningful place (Janoff-Bulman, 1992). However, traumatic events, such as strokes, HIV positive diagnoses, and death of a loved one, may challenge the sense of meaning. Being able to find meaning in the negative event helps restore this fundamental assumption, which is possibly why the ability to find meaning has been linked with positive outcomes. Since religious traditions typically offer believers a sense of meaning and purpose in life, it seems likely that spiritual struggles may be even more harmful for individuals because they threaten one context from which meaning is provided. Being able to find meaning from a struggle, then, may help individuals preserve and protect a fundamental assumption, allowing them to grow from this event.

\section{Religious History}

Many factors combine to form an individual's religious history. Of particular relevance to predicting the outcomes of spiritual struggles are the extent to which religious beliefs are integrated into one's life and an individual's attachment to God.

Religious Integration. Religious integration is the degree to which an individual's religious beliefs are incorporated into all aspects of his/her life. How much an individual 
integrates religious beliefs into his/her life may be related to the outcome of a spiritual struggle. A longitudinal study with parents that experienced the death of a child due to Sudden Infant Death Syndrome (SIDS) provides an example of the importance that religious integration has on well-being and distress (McIntosh, Silver, \& Wortman, 1993). In this study, the relationship between religious integration (indirectly measured by importance of religion and religious participation), coping variables (finding meaning, social support, and cognitive processing), and adjustment (depression and well-being) was investigated. In a larger path-analysis, greater religious integration was directly related to finding more meaning in the event and to more cognitive processing and was indirectly related to increased well-being and decreased distress.

Another relevant study investigated the relationship between religious doubting and emotional distress in high school students from Catholic and Protestant parochial schools (Kooistra \& Pargament, 1999). Religious doubting was consistently associated with negative mood and anxiety for Protestant students (correlations ranged from .30 to $.37, p<.001$ ), but not for Catholic students. The groups also differed on their degree of religious integration. Specifically, Protestant students endorsed greater frequency of individual and parental church attendance and more intrinsic religiosity; indicating that they had a higher degree of religious integration. These findings imply that spiritual struggles may cause more distress for individuals whose religion is well integrated into their life.

These results seem to contradict the findings by McIntosh, Silver, and Wortman (1993) which indicate that religious integration is related to better psychological adjustment. This discrepancy may be explained by differences in timing and in the type 
of negative event: Kooistra and Pargament investigated distress during a religious negative event (during religious doubting), whereas McIntosh, et al. investigated adjustment after a secular negative event (after the loss of the child). First, the resolution of the negative event may impact the outcome of the struggle. The high school students were asked about a current negative event, current religious doubts, indicating that their doubts had not yet been resolved, whereas the parents reflected on a past negative event. Second, the nature of the negative event also may help explain the difference in findings between the two studies: religious integration may have different implications for a spiritual struggle than for a secular traumatic event. Having greater religious integration seems to have helped the adults cope with the death of their child. It may be easier to mobilize religious resources when one’s religion is well-integrated into one’s life. Therefore, parents with better religious integration may have had more access to religious resources to help them cope with and process the event. However, for students with greater religious integration, their doubts would likely have caused them more distress because they were doubting something that was central to their lives.

A study of religious coping among Presbyterian clergy, elders, and members supports the argument that spiritual struggles are more distressing for individuals whose religion is central to their lives (Pargament, Tarakeshwar, Ellison, \& Wulff, 2001). This study investigated the impact of positive and negative religious coping in a national sample of Presbyterian clergy, elders, and members. It is logical to assume that religion is more central to the lives of clergy and elders than for members. Of particular relevance were the findings pertaining to negative religious coping: negative religious coping was associated with decreased positive affect (correlations ranging from -.33 to -.68, $p<.01$ ) 
and increased depressive affect $(.52$ to $.59, p<.01)$ for all three groups, especially for clergy and for elders. Moreover, negative religious coping was related to decreased religious satisfaction only for clergy and elders $(r=-.08, p<.05 ; r=-.06, p<.05$, respectively). In light of these results, the authors suggested that "For better or worse then, it appears that religion has more significant effects for those whose roles and identities are more closely tied to religion,” (p. 510).

Extending these findings to spiritual struggles, it seems likely that the more integrated an individual's religious beliefs, the more distress he/she will experience from the struggle initially. However, in terms of predicting outcome following a spiritual struggle, greater religious integration would likely be predictive of growth.

God Attachment. The relationship between an individual and God is central to most religious traditions. Therefore, defining characteristics of this relationship would seem to be important in predicting the outcome of a spiritual struggle. Attachment style is an important characteristic of a relationship. Research has established that attachment to God is predictive of mental and physical health, personality characteristics, and coping styles (e.g., Kirkpatrick \& Shaver, 1992; Rowatt \& Kirkpatrick, 2002). Moreover, God attachment styles have been found to add power above and beyond the effects of other religious variables, such as loving God images, intrinsic religiosity, and doctrinal orthodoxy, in predicting outcomes, specifically affect and personality (Rowatt \& Kirkpatrick, 2002).

Research on a sample of adult community members responding to a newspaper survey and a sample of undergraduate students differentiated between three types of attachment styles: secure, avoidant, and anxious/ambivalent (Kirkpatrick \& Shaver, 1992; 
Weinborn, 1999). Secure attachment to God is characterized by feelings of warmth, support, and protection. Individuals with an avoidant attachment to God view God as impersonal, distant, and uninterested in their problems. For individuals with an anxious/ambivalent attachment to God, God appears inconsistent, sometimes exhibiting love and care and sometimes seeming distant and uninterested. Specifically, secure attachment to God predicted greater life satisfaction and religious well-being; avoidant attachment to God was associated with lower levels of competence, life satisfaction, and religious well-being; and anxious/ambivalent attachment to God was associated with more anxiety and depression, poorer physical health, and lower life satisfaction (Weinborn, 1999; Kirkpatrick \& Shaver, 1992).

Belavich and Pargament (2002) investigated associations between God attachment and religious coping and discontent in individuals waiting for a loved one undergoing inpatient surgery. Secure God attachment styles were correlated with greater positive spiritual coping strategies (correlations ranging from .37 to $.49, p<.001$ ) and with less religious discontent $(r=-.29, p<.001)$. Moreover, anxious attachment was correlated with increased religious distress. Kirkpatrick and Shaver (1992) investigated God attachment styles in a community sample. They found that individuals reporting secure relationships with God reported greater life satisfaction and less anxiety, loneliness, physical illness, and depression than other individuals. Moreover, the avoidant attachment group had the highest proportion of agnostics, $20 \%$ compared to $14.1 \%$ for anxious/ambivalent and $12.6 \%$ secure. The anxious/ambivalent group had the highest proportion of atheists, though the difference was not statistically significant. 
Rowatt and Kirkpatrick (2002) provided another illustration of the predictive power of attachment style. Researchers surveyed 374 individuals from community and undergraduate samples and found that anxious attachment to God was a significant predictor of neuroticism $(\beta=.25, p<.001)$, negative affect $(\beta=.24, p<.01)$, and decreased positive affect ( $\beta=-.15, p<.05$ ). On the other hand, avoidant attachment was predictive of less agreeableness $(\beta=-.28, p<.05)$. These results were found after controlling for other religious variables_-intrinsic religiosity, doctrinal orthodoxy, and loving God images — and for social desirability.

Simpson (2002) theorized that secure attachment styles may help reduce religious doubts for an individual. High levels of dependence and attachment on others can create feelings of vulnerability in an individual. This feeling of vulnerability may be exacerbated in the face of a struggle. Individuals typically will try to reduce feelings of vulnerability through different cognitive strategies. Simpson speculated that the general approach used to reduce these feelings of vulnerability is to attribute more importance to the attachment figure, highlighting strengths and downplaying weaknesses. Doing so would help reduce feelings of vulnerability and increase feelings of security. In terms of religious attachment, being able to highlight God's perceived strengths and to ignore or downplay perceived weaknesses may help reduce religious doubting and help sustain religious beliefs. It is probable that individuals with secure God attachment styles will engage in cognitive strategies that help reduce feelings of vulnerability, especially during a spiritual struggle.

In light of this research, attachment to God seems to be a potentially valuable predictor of the outcomes of a spiritual struggle. Individuals with secure attachments 
likely experience spiritual struggles, as do individuals with anxious and avoidant attachment styles. What differentiates these individuals may be the outcome of the spiritual struggle. It is hypothesized that secure God attachment will lead to growth, whereas avoidant and ambivalent attachments will lead to decline.

\section{Support}

Social support and religious social support are potentially valuable resources for individuals experiencing a spiritual struggle. Research on a range of stressors and populations has demonstrated the positive effects that receiving support from others has on an individual. The same positive benefits are likely to be associated with spiritual struggles.

Secular Social Support. Relationships between social support, psychological factors (including depression, negative coping strategies, and post-traumatic growth) and physical health (including physical recovery and disease progression) following stressful life events have been demonstrated in a variety of contexts. One study of individuals in a cardiac rehabilitation program investigated the relationship between social support and coping, depressive symptoms, and physical health (Shen, McCreary, \& Myers, 2004). The researchers found that higher levels of social support were associated with less use of negative coping strategies $(r=-.19, p<.01)$, lower amounts of depressive symptoms $(r=$ $-.49, p<.01$, and increased physical recovery $(r=.41, p<.01)$. In a larger path analysis, social support significantly predicted physical functioning $(0.29$, total effects; 0.15 direct effects; and 0.14, mediational/indirect effects). These findings were significant after controlling for baseline health and other psychosocial variables. 
Social support has also been found to impact the progression of AIDS in HIV positive men (Leserman et al., 1999). In a longitudinal study of asymptomatic HIV positive men, lower amounts of social support satisfaction increased the rate of progression of HIV to AIDS. Specifically, after 5.5 years, individuals receiving less than the median amount of social support had a two to three times increased likelihood of developing AIDS: 24\% of individuals receiving more than the median amount of social support developed AIDS compared to $49 \%$ of those receiving less than the median. Moreover, it was found that the number of people giving social support did not impact disease progression; instead, it seems that the satisfaction with the support was more important.

Social support has also been linked with positive implications for bereaved caregivers of HIV/AIDS patients (Cadell, Rogeher, \& Hemsworth, 2003). This study investigated the role that social support has on growth after a traumatic event, the death of a loved one. Based on structural equation modeling, it was found that social support had a positive and direct effect on growth $(0.21, p<.05)$. These findings imply that increases in social support help contribute to increases in post-traumatic growth.

These last two studies are of particular relevance to spiritual struggles. Both HIV and AIDS and spiritual struggles are topics that may be stigmatized. Because of these stigmas, individuals and caregivers for individuals with HIV or AIDS and individuals struggling with their spirituality may not feel able to seek support from others. Instead, they may suppress their need for support for fear that they will be stigmatized. The individual experiencing a struggle who feels socially isolated may decline, while the person who is able to find sources of support in the midst of a struggle may grow. 
Religious Support. In addition to secular sources of social support, the availability of religious sources of support, such as God, clergy, or spiritual support from congregation members, may influence whether individuals grow or decline following a spiritual struggle.

Religious and social support appear to make unique associations with outcome variables, specifically positive religious coping (Krause, Ellison, Shaw, Marcum, \& Boardman, 2001). Krause et al. used a survey of members from the Presbyterian Church USA to investigate the relationships between emotional and religious support from congregation members and emotional support from the pastor and religious coping. For the purpose of this study, both religious support from congregation members and emotional support from the pastor were classified as types of religious support. Religious support from the congregation was significantly associated with increased religious coping $(r=.40, p<.001)$. Emotional support from the pastor was also significantly correlated with use of religious coping, however not as strongly $(r=.12, p<.05)$. However, no significant results were found for emotional support from congregation members. The results indicated that secular, emotional support from congregation members, and religious support, religious support from congregation members and emotional support from pastor, were correlated, but not so highly as to suggest they were identical. Based on these results, it is important to investigate religious and secular social support separately.

Research has found that religious support is an important source of support for individuals (Chalfant et al., 1990). For example, individuals from a stratified random sample from Texas turned to clergy more than mental health professionals, medical 
doctors, and lawyers when faced with personal problems. Specifically, $41 \%$ of this survey of 806 community members indicated that they would turn to clergy for a personal problem compared to $21 \%$ who said they would turn to psychologists.

Maton (1989) speculated that religious support would be mobilized in high-stress situations and that it might be more efficacious in these situations. He investigated two different high and low-stress populations: adults who had lost a child within the past two years (high stress); adults who had lost a child more than two years ago (low stress); and college students (high and low stress samples were identified using a life stress measure). For both adults and college students, only the samples characterized as "high stress" were significantly related to outcome. For example, in the high stress adults sample, religious support was significant correlated to decreased depression $(r=-.33, p<.05)$ and increased self-esteem $(r=.42, p<.01)$. Moreover, based on regression analysis, spiritual support explained $8 \%$ of unique variance in depression $\left(\Delta \mathrm{R}^{2}=.08, \beta=-.21, p<.04\right)$. Similar results were found for the high-stress college student sample. Specifically, spiritual support was related to increased personal adjustment $(r=.47, p<.01)$. Moreover, in regression analysis, spiritual support predicted $12 \%$ of unique variance in personal adjustment $\left(\Delta \mathrm{R}^{2}=.12, \beta=.46, p<.025\right)$

Thompson and Vardman's (1997) study on adjustment to a family member killed by homicide also provides support for the benefits of religious support. They found that religious support was the only religious variable significantly related to lower posthomicide distress $(r=-.17, p<.05)$.

Overall, research indicates that support received from religious sources following a traumatic experience significantly influences well-being, with more support related to 
positive outcomes. Conversely, the lack of religious support may be problematic. In this vein, research on religious communities indicates that communities differ in their expressiveness, the degree to which members encourage the open expression of feelings (Pargament, Silverman, Johnson, Echemendia, \& Snyder, 1983). Individuals belonging to religious communities low in expressiveness may be hesitant to discuss their spiritual struggle. Because spiritual struggles involve sacred issues that are deeply personal, individuals in some communities may be hesitant to seek religious support for fear of stigmatization. This fear is partly founded: it may be difficult for individuals to find religious support for religious struggles. A letter that one mother wrote to her daughter's university in response to the university's recent incorporation of evolution into their curriculum is one example of this: “If her [the daughter's] faith is shattered or shaken, I'd rather see her dead,” (Neeson, 2001). Thus, religious support may not always be available for individuals struggling spiritually. Based on the findings discussed above, it appears that receiving religious support may be tied to growth, while the lack of religious support may be tied to decline.

\section{Positive Religious Coping ${ }^{1}$}

Individuals use a variety of techniques to cope with stressful life events. Positive religious coping strategies are one way to handle these events. Empirical evidence suggests that certain religious coping strategies help individuals grow through secular negative events. This same relationship may also hold true for spiritual struggles.

\footnotetext{
${ }^{1}$ Secular coping strategies are possibly related to the outcome of a spiritual struggle. However, the secular coping measure was unintentionally left out of the survey. Therefore, only positive religious coping was assessed.
} 
Specific religious coping techniques have been identified that lead to mental and psychological growth. These include Benevolent Religious Reappraisal, Collaborative Religious Coping, Religious Purification, and Spiritual Connection. Benevolent Religious Reappraisal involves the use of religion to redefine a negative event as potentially beneficial. Collaborative Religious Coping involves seeking a partnership with the divine to help cope with a stressor. Religious Purification is defined by the search for spiritual cleansing and peace through religious actions. Lastly, Spiritual Connection consists of the search for a connection with the divine in response to a negative event (Pargament, Koenig, \& Perez, 2000). These strategies have been found to be beneficial for both college students experiencing a negative event (Pargament, Koenig, \& Perez, 2000) and for a sample of elderly, hospitalized patients (Koenig, Pargament, \& Nielson, 1998). Specifically, Benevolent Reappraisal and Collaborative Religious Coping were associated with increased stress-related growth and spiritual growth; Religious Purification was related to increases in spiritual growth and stress-related growth; and Spiritual Connection was correlated with enhanced quality of life, stress-related growth, and spiritual growth (correlations ranged from .25 to .70, $p<.01$ ). Additionally, for hospital patients, these coping strategies were generally related to decreased depression and increased quality of life (correlations ranging from .09 to .11, $p<.05$ ).

These results were found for individuals experiencing secular life stressors. However, since these are religious coping strategies, it is likely that they will impact spiritual struggles in the same way. Specifically, it is likely that the use of these religious coping strategies, Benevolent Religious Reappraisals, Collaborative Religious Coping, Religious Purification, and Spiritual Connection, will be related to increased growth. 


\section{The Present Study}

The purpose of the present study was to help distinguish between the paths leading to growth and decline subsequent to spiritual struggles. Until now, research has focused on (1) identifying the predictors of spiritual struggles and (2) identifying the outcomes of spiritual struggles. However, as yet, it is unclear what determines whether struggles will lead to growth or decline. The aim of this project was to fill this gap in the literature about spiritual struggles. Specifically, this project attempted to identify and distinguish between those pathways leading to growth and decline following spiritual struggles.

A college student sample was used for this study. This sample was preferable because college is a time of change for adolescents, particularly religious change. For most students, college is their first opportunity to live away from their family and to interact with individuals with different religious beliefs. Moreover, as cited above, roughly half of college students, at any given time, are experiencing spiritual struggles.

In this study, college students in the midst of intrapsychic or divine struggles were identified. After being identified, the students completed a battery of questionnaires that assessed predictor dimensions (spiritual struggle characteristics, religious history, support, and religious coping) and indicators of the impact of the current struggle. These individuals were contacted four to six weeks later to assess whether they were still experiencing the struggle. Additionally, they completed several indicators assessing the degree to which they experienced growth or decline subsequent to their struggle.

Based on the above discussion, it was hypothesized that:

1. For spiritual struggle characteristics: 
a. Initial stressfulness of the struggle will be related to more growth and less decline.

b. Ability to find meaning from the struggle will be related to more growth and less decline.

2. For religious history variables:

a. Greater religious integration will be related to more growth and less decline.

b. Secure attachment to God will be related to increased growth, while avoidant and ambivalent attachment to God will be related to increased decline.

3. For support variables:

a. The perception of social support will be related to more growth and less decline.

b. Receiving religious support will be related to increased growth and less decline.

4. Religious coping strategies will be related to more growth and less decline. 


\section{METHODS}

\section{Sample Characteristics}

The sample $(n=127)$ consisted of undergraduate students from a Midwestern university who volunteered for the study to receive extra credit in an introductory psychology course. The majority of participants were female $(71.7 \%$, male $=28.3 \%)$, with an average age of 19 years, ranging from 18 to 40 years. In terms of religiousness, 48.8\% of the sample identified as Protestant, 34.6\% identified as Catholic, 5.5\% indicated being unsure or identified themselves as having "no" religious affiliation, 3.9\% identified as agnostic, 2.4\% identified as a non-traditional religious affiliation (Kemetic, Ba'hai), and 1.6\% identified as Jewish. With respect to spiritual struggle, on average, participants endorsed between a little bit and moderate degree of struggle (intrapersonal struggle $M=2.72$, divine struggle $M=2.49$, with the scale ranging from 1 to 5 ).

\section{Procedure}

\section{General Administration}

Data were collected through a web survey on two occasions separated by four to six weeks. For their involvement in the study, participants who were eligible for the study earned extra credit in an introductory psychology class. Credit was only awarded to those who completed both parts of the study. At time one, students completed a battery of questionnaires, which assessed for current spiritual struggles, predictor variables, and outcome measures. After four to six weeks, students were contacted by e-mail and asked to complete the second web-survey. The second survey assessed the current status of the participant's spiritual struggle, their ability to find meaning from the struggle, and the impact of the struggle on the participant's life. Since the survey was web-based, the order 
of the variables was not randomized. Instead, all participants completed the battery in the same order. Refer to Table 1 for a list of the variables assessed at each time point. Screening

A screening questionnaire was administered to individuals in introductory psychology classes. This questionnaire consisted of a single item assessing for divine spiritual struggle, a single item assessing for intrapsychic spiritual struggle, and modified items from the Negative Religious Coping scale (NRCOPE). Intrapsychic and divine spiritual struggles were assessed using a single item each. To assess for intrapsychic struggles, participants were asked, “Currently, to what extent are you experiencing personal conflict regarding your religious beliefs, doubts about religion, or questions about God.” To assess for divine struggles, participants were asked, “Currently, to what extent are you experiencing any tension in your relationship with God, such as confusion, anxiety, loneliness, frustration, anger, abandonment, or guilt.” Participants responded to these questions using a 5-point scale, ranging from 1, not at all, to 5, extremely. Eligibility was determined by an endorsement of a 2 (a little bit) or greater on either of these single items.

In addition to the single items, a modified version of the Negative Religious Coping scale was administered. The modified version included items from the Spiritual Dissatisfaction (two items) and Punishing God Appraisals (four items) subscales. Twelve new items were added to this scale to assess for spiritual struggles more thoroughly. Participants responded to the NRCOPE items using a 4-point scale, ranging from not at all to a great deal. The NRCOPE items were used to substantiate the participant's responses to the single items assessing for spiritual struggle. If a student was eligible 
based on the responses to the single items, then their responses on the NRCOPE were examined. Students had to endorse at least a 2, a little bit, on one of the NRCOPE items; if they answered not at all to each of these items, they were no longer eligible for the study.

The screening questionnaire was administered to 332 students from introductory psychology discussion classes. Of these, 68.9\% $(n=229)$ endorsed current struggle, defined as experiencing at least "a little bit” of intrapersonal or divine struggles assessed by the questions described above. These students were contacted within one week via email and were asked to participate in the study. Students were informed that participation involved completing a web-survey at two time points, separated by four to six weeks. To receive extra-credit, the participants had to complete both surveys. Sixty-two percent ( $n=$ 142) of the eligible students successfully completed the first survey. Four to six weeks later, these students were contacted again and asked to complete the second web-survey. Eighty-nine percent $(n=127)$ of students completed the second survey.

\section{Attrition}

Students who did not complete the second survey were excluded from the analyses. These students were similar to the participants of the study in several respects. First, these students were mainly female $(60 \%, n=9$; males $=40 \%, n=6)$. Second, the average age was 19 years, with a range of 18 to 20 years. Lastly, the amount of struggle endorsed was similar: the average score for intrapersonal struggle was 2.67 (compared to $M=2.72$ ). The average score for divine struggle was 2.33 (compared to $M=2.49$ ). However, the students who did not complete the second survey differed in religious 
affiliation. Specifically, the majority of non-completers were Catholic $(60 \%, n=9)$, whereas Protestantism was the most endorsed religion for study participants (48.8\%).

$$
\text { Spiritual Struggle Measures }{ }^{2}
$$

Current levels of spiritual struggle were assessed at time one using the items from the screening questionnaire (refer to the screening section for a detailed description of the measurement of struggles). Specifically, the single item assessing for intrapsychic struggle and the single item assessing for divine struggle was administered at time one. However, the modified NRCOPE was administered at both time points. These items were used to substantiate participant's endorsement of struggle and were used to determine whether struggle levels changed over time (described below). For this study, the modified Negative Religious Coping scale and subscales demonstrated good psychometric properties $^{3}$. With respect to the reliability of these items, for the total scale $\alpha=.96$ (at time two, $\alpha=.96$ ), for Spiritual Dissatisfaction subscale $\alpha=.80$ (at time two, $\alpha=.82$ ), for Punishing God Appraisals, $\alpha=.71$ (at time two, $\alpha=.72$ ), for the new items, $\alpha=.86$ (at time two, $\alpha=.88$ ).

\section{Predictor Measures}

\section{Struggle Characteristics}

Struggle Severity. The Impact of Event Scale (IES) was used to assess the severity of the spiritual struggle (Howorwitz, Wilner, \& Alvarez, 1979). Struggle severity was assessed at time one. The IES has a total of 15 items which are divided into two subscales, the Intrusion subscale (seven items) and the Avoidance subscale (eight items). In the current study, the IES was slightly modified by asking participants to respond

\footnotetext{
${ }^{2}$ Predictor measures are in Appendix A.

${ }^{3}$ Internal consistencies for current study are in Table 2.
} 
specifically about their spiritual struggle, instead of leaving the negative event vague, as in the original scale. For instance, one item from the original IES is "I thought about it when I didn’t mean to.” In the current study, the word “it” was replaced with “my spiritual struggle.” Participants were asked to rate the frequency (not at all, rarely, or often) at which they experienced these modified items.

This scale has demonstrated good psychometric properties. Specifically, the internal consistency coefficients for the Intrusion and the Avoidance subscales are $\alpha=$ .79 and $\alpha=0.82$, respectively. Although the authors do not report on the reliability of the total scale, in the current study, the IES total score was used instead of the subscales and the reliability for the IES in this study was $\alpha=.88$.

Meaning. A single item was used to assess the ability to find meaning from the spiritual struggle at time two. Meaning was the only predictor variable assessed at this time point. Participants were asked to indicate the degree to which they had found meaning in their struggle using a 5-point scale, ranging from 1, not at all, to 5, yes, a great deal. Researchers have assessed for meaning with single items in other studies and reported significant findings (McIntosh, Cohen Silver, \& Wortman, 1993; Murphy, Johnson, \& Lohan, 2003; Thompson, 1991). For example, Thompson asked participants whether they had "found any meaning in [their] experience with a stroke," ( $p$. 86). In Thompson's study, 50\% of stroke patients' and 45\% of caregivers' responses indicated that they found meaning.

\section{Religious History}

Religious Integration. The Compartmentalized Religion Scale was used to assess the degree to which an individual's religion is integrated into other areas of his or her life. 
This was assessed at time one. The original scale consisted of two items, "Religion is only one part of my life" and "I wouldn’t let my religion become more important to me than my friends or family,” which had low internal consistency, $\alpha=.43$ (cf Weinborn, 1999). However, these items produced significant results: high compartmentalization predicted low self-esteem and increased racial prejudice and dogmatism. Weinborn (1999) added three items to this scale, which increased the reliability ( $\alpha=.77$ ). Moreover, using this 5-item scale, greater compartmentalization was related to lower competence, life satisfaction, and religious well-being (Weinborn, 1999). In the current study, the 5-item scale was utilized. Participants reported the degree to which they agreed with the items, with response choices ranging from 1, strongly disagree to 5, strongly agree. The responses were reverse coded so that greater scores were indicative of greater religious integration. This scale demonstrated good psychometric properties $(\alpha=.80)$ for the current study.

God Attachment. Attachment to God was measured at time one using a scale developed by Rowatt and Kirkpatrick (2002). This scale is based on Kirkpatrick and Shaver's (1992) God Attachment Scale. The original scale assessed for avoidant attachment, anxious attachment, and secure attachment styles. Based on advances in attachment literature, Rowatt and Kirkpatrick developed a nine item scale which assesses for two attachment styles, avoidant and anxious. They authors theorized that avoidant and secure attachment styles were two ends of the same construct instead of two distinct subscales. This scale was validated on a sample of community members and undergraduate students. The internal consistency was found to be high for both avoidant $(\alpha=.90)$ and anxious $(\alpha=0.80)$ attachment styles. Although Rowatt and Kirkpatrick 
conceptualized attachment to God as two distinct styles, they reported that factor analysis supported three distinct factors. For this study, the three-factor model was used, with avoidant, anxious, and secure attachment styles treated as separate subscales. Each subscale consisted of three items. For example, "God seems impersonal to me” is a question used to assess avoidant attachment; "I have a warm relationship with God” is a question used to assess secure attachment; and "God sometimes seems very warm and other times very cold to me,” is a question used to assess anxious attachment. Participants were asked to indicate whether they agreed (1) or disagreed (2) with each item. The total subscale scores were reverse coded so that higher scores were indicative of greater endorsement of that specific attachment style. Secure attachment and avoidant attachment had adequate internal consistencies ( $\alpha=.70$ and $\alpha=.83$, respectively). However, anxious attachment had a relatively low internal consistency $(\alpha=.58)$.

\section{Support}

Social Support. There are several ways to measure social support. For example, social support can be measured by the density of the social network, the amount of perceived support, and the amount of received support (Sarason \& Sarason, 1994). These different assessment tools have yielded different patterns of results. However, research has consistently found that perceived social support is particularly advantageous for individuals (Antonucci \& Israel, 1986; Sarason \& Sarason, 1994). Based on these findings, perceived social support appears to be most appropriate for this study.

Perceived social support, which was assessed using The Multidimensional Scale of Perceived Social Support (MSPSS), was assessed at time one (Zimet, Dahlem, Zimet, \& Farley, 1988). This 12 item scale is designed to measure perceptions of social support 
adequacy from three sources: family, friends, and significant other. Individuals are asked how much they agree with items statement such as "I get the emotional help and support I need from my family” using a 5-point scale, ranging from 1, strongly disagree to 5, strongly agree. This scale has shown good internal consistency, with reliability coefficients ranging from $\alpha=.85$ to .91 . Specifically, internal consistencies were .88 for the total MSPSS score, .85 for Friends, .87 for Family, and .91 for Significant Other. This scale was correlated negatively with anxiety and depression (Zimet, Dahlem, Zimet, \& Farley, 1988). The MSPSS had similar internal consistencies for the current study, with $\alpha$ ranging from .85 to .92 (Significant Other: $\alpha=.92$; Family: $\alpha=.85$; Friends: $\alpha=.89$; and MSPSS total: $\alpha=.90)$. The individual subscales were utilized in analyses because they provide specific information about the types of support that are stronger predictors of growth and decline.

Religious Support. The Religious Support Scale was used to assess religious support, which was assessed at time one (Fiala, Bjorck, \& Gorusch, 2002). This instrument has 21 items, which are divided into three subscales: God, Congregational, and Religious Leader Support. Each subscale is composed of seven items. In the scale, individuals rated how much they agreed with items such as, "God gives me the sense that I belong,” on a 5-point scale, ranging from 1, strongly disagree, to 5, strongly agree.

The Religious Support Scale and its subscales have been found to have good internal consistency with the following reliability coefficients, $.91, .91, .90$, and .75 for the total scale score, support from congregation, support from religious leader, and support from God, respectively. Additionally, congregational and religious leader support were highly correlated ( $r=.75$ ) and these two subscales are significantly, but modestly, 
correlated with the God subscale $(r=.24)$. The Religious Support scale was associated with social support, decreased depression and increased life satisfaction (Fiala, Bjorck, \& Gorusch, 2002).

The Religious Support Scale demonstrated good psychometric properties for the current study. Specifically, the internal consistency coefficients were: $\alpha=.91$ for congregational, $\alpha=.93$ for religious leader, $\alpha=.87$ for God, and $\alpha=.94$ for the entire scale. However, the congregational and the religious leader subscales were highly correlated, $r=0.91$, which poses a risk for multicollinearity. Therefore, only two subscales, support from God and from congregation, were utilized for this study. The subscales were utilized, opposed to a total scale score, in analyses because they provided specific information about the types of religious support that were the most predictive of the criterion measures.

Positive Religious Coping

Specific subscales from the Positive Religious Coping Scale (PRCOPE), a scale developed by Pargament, Koenig, and Perez (2000), were used to assess for specific religious coping methods at time one. Specifically, four subscales from the PRCOPE were used in this study: Benevolent Religious Reappraisal, Collaborative Religious Coping, Religious Purification, and Spiritual Connection. The Religious Purification subscale consists of 10 items, such as “Tried to be less sinful.” The Benevolent Religious Reappraisal subscale consists of 8 items, such as “Saw my situation as part of God’s plan.” The Collaborative Religious Coping subscale consists of 8 items, such as "Worked together with God as partners.” Lastly, the Spiritual Connection subscale consists of 3 items, such as “Tried to experience a stronger feeling of spirituality.” The individual is 
asked "how much or how frequently" each strategy is used to cope with the spiritual struggle on a 4-point scale, with answers ranging from 1, not at all, to 4, a great deal. Each of the subscales has demonstrated strong internal consistencies, ranging from .81, for Spiritual Connection, to .93, for Religious Purification. The reliabilities of each of these subscales for the current study were consistent with previous findings, with coefficients ranging from .83 to $.95: \alpha=.83$ for Spiritual Connection; $\alpha=.86$ for Collaborative Coping; $\alpha=.89$ for Benevolent Religious Reappraisals; and $\alpha=.94$ for Religious Purification.

\section{Outcome Measures ${ }^{4}$}

\section{Growth}

Struggle-Related Outcome. Participants were asked how their spiritual struggle has affected them at time two. Specifically, they were asked to respond to the following question, “As a result of my spiritual struggle, I have," with the following response choices: grown, declined, both grown and declined, or neither grown nor declined. The response choices were intentionally ambiguous, allowing the participant to interpret and respond to the terms as they saw fit. To clarify their responses, the participants were asked to briefly describe the struggle's impact on their life. These free-responses provided meaningful descriptive information about the different impacts that spiritual struggles can have on participants.

Posttraumatic Growth. Secular growth following the spiritual struggle was assessed using the Posttraumatic Growth Inventory, at both time points (Tedeschi \& Calhoun, 1996). The scale measures positive changes that individuals experience

\footnotetext{
${ }^{4}$ Outcome measures are in Appendix B.
} 
subsequent to traumatic events. In this study, the spiritual struggle was the traumatic event. The Posttraumatic Growth Inventory (PTGI) consists of 21 items that are categorized into five subscales, including Relating to Others, New Possibilities, Personal Strength, Spiritual Change, and Appreciation of Life. The Spiritual Change subscale was not used because spiritual growth was measured with a separate assessment tool (described below). In the PTGI, participants rated how much change they had experienced on items such as “My priorities about what is important in life,” using a 6point scale, ranging from 1 , I did not experience this change to 6, I experienced this change to a very great degree. The original instructions, "As a result of my crisis...” were slightly modified, substituting the phrase "my spiritual struggle” for "my crisis." For this study, the total PTGI score was used, instead of the subscales. The PTGI demonstrated good internal consistency at both time points ( $\alpha=.95$ for both times).

Life Satisfaction. The Satisfaction with Life Scale (SWLS) was used as a general indicator of life satisfaction at both time points (Diener, Emmons, Larsen, \& Griffen, 1985). This scale has demonstrated good psychometric properties. Specifically, the SWLS has good internal reliability $(\alpha=.87)$ and test-retest reliability $(r=.82)$.

The scale consists of five items that assess for general life satisfaction. Participants are asked to rate how much they agree with items such as, "In most ways my life is close to ideal” using a 7-point scale, ranging from 1, strongly disagree, to 7, strongly agree. These five items demonstrated good internal consistency in this study (time one $\alpha=.86$; time two $\alpha=.85$ ).

Spiritual Growth. Spiritual growth was assessed at both time points using items from the Spiritual Changes Questionnaire, a scale being developed by Brenda Cole. This 
scale consists of 50 questions assessing for spiritual change in individuals diagnosed with cancer, however only five items from this scale were utilized for this study. For these items, participants were asked, “Thinking about your spiritual struggle, how much do you agree with the following statements.” They rated their agreement with the items on a seven-point scale, ranging from 1, not at all, to 7, a great deal. In this study, the reliability for the 5-item scale was .86 at time one and .90 for time two.

Resolvability. A single item at time two was used to assess the current status of the spiritual struggle. Participants were asked to respond to the following question, "I feel that my spiritual struggle has...” with the following response choices: been completely resolved, been partially resolved, not changed, or become worse. Additionally, NRCOPE scores from time 1 and time 2 were compared to assess for change in struggle intensity. Declines in this score indicated decreases in amount of spiritual struggle. Pargament, Koenig, Tarakeshwar, and Hahn (2004) also compared negative religious coping scores at baseline and follow-up in their study on medically ill inpatients as an indicator of chronic struggle. For their study, chronic strugglers, individuals who endorsed significant struggles at baseline and at follow-up, had an increased risk declines in physical and mental health.

Decline

Global Distress. Global distress was assessed using the Brief Symptom Inventory (BSI) at both time points (Derogatis \& Spencer, 1975). The BSI consists of nine subscales; however only the subscales measuring depression, anxiety, and hostility were used. Together, these subscales have 16 items: six items for the Depression subscale, six items for the Anxiety subscale, and five items for the Hostility subscale. Participants 
were asked to rate how much each item, such as "Nervousness or shakiness inside” has “distressed or bothered” them using a five point scale, ranging from 1, not at all, to 5, extremely. Each subscale has been found to have modest internal reliabilities, ranging from .78 , for the Hostility subscale, to .85 for the Depression subscale. In this study, the total score for the BSI was used as an indicator of global distress. The total demonstrated good reliability at both times: $\alpha=.94$ at time one and $\alpha=.93$ at time two.

Spiritual Decline. Spiritual decline was assessed at both time points using 5 items. These items paralleled the items used to assess spiritual growth, focusing on decline, rather than growth. Participants were asked to rate their agreement to items such as "In some ways I have shut down spiritually” using a 7-point scale, ranging from 1, not at all to 7, a great deal. These items were reliable at both time points. Specifically, $\alpha=.85$ at time one and .89 at time two. 


\section{RESULTS}

\section{General Procedure}

The first step of the statistical analyses was to calculate descriptive statistics (including means, standard deviations, possible and actual ranges, and internal consistency ratings) for the demographic, predictor, and criterion variables. Next, participants' descriptions of their struggle were content analyzed. Then, the relationships between demographic variables and criterion measures were analyzed using a bivariate correlation matrix and a one-way ANOVA to identify variables that needed to be controlled in subsequent analysis. Demographic variables related to criterion measures served as controls in subsequent analyses. Following that, correlations between the predictors and criteria at time two were conducted. Finally, separate hierarchical multiple regression equations were run for each predictor category (i.e.,, struggle characteristics, religious history, support, and religious coping) and each criterion measure (i.e.,, posttraumatic growth, satisfaction with life, spiritual growth, resolvability, distress, and spiritual decline). These regression equations were constructed in two steps. Control variables were entered into the first step of the equation (including time one variables in those instances in which change between time one and time two was assessed). In the second step, variables from each predictor category were entered. Variables from each predictor category that accounted for unique variance were then identified and standardized beta weights were examined for statistical significance. Significant variables from each predictor category were then entered into a final hierarchical multiple regression equation to identify those variables most strongly predictive of the criterion measure. 


\section{Preliminary Analyses}

Descriptive statistics, including means, standard deviations, possible and actual ranges, and internal consistency ratings, when appropriate, were calculated for all scales used in this study and are presented in Table 2. In general, the sample endorsed a low level of spiritual struggles. Additionally, the sample reported receiving a great amount of social support, from their family, friends, and significant other. At time two, participants generally were experiencing low levels of global distress and meaning, and high levels of life satisfaction.

Next, potential relationships between demographic variables and outcome variables were identified using ANOVAs and correlations. Specifically, analyses of variance were calculated for gender and religion for each criterion measure and correlations for age were calculated for each criterion measure. None of these demographic variables was significantly related to the outcome measures. Therefore, they were not used as controls for the hierarchical regression equations.

Intercorrelations among the predictor variables were calculated to identify potential multicollinearity. It has been suggested that correlations greater than $r>.80$ generate problems of multicollinearity (Licht, 1996). In the current study, most intercorrelations among predictor variables ranged from $(r=.18$ to $r=.78)$. However, two subscales from the Religious Support Scale, congregational and religious leader, were highly intercorrelated, $r=.91$. To avoid potential problems of multicollinearity, only one of these subscales, congregational, was utilized in this study.

Based on the single items assessing for intrapsychic and divine spiritual struggles, participants reported experiencing between a little bit to moderate amounts of spiritual 
struggle (average intrapsychic struggle $=2.72$, average divine struggle $=2.49$ ). Based on a paired-sample $t$-test, participants reported significantly greater intrapersonal struggles than divine struggles $(t(126)=2.59, p<.05)$. These findings were substantiated by participants' descriptions of their struggles. Based on the content analysis, $47.2 \%$ of the sample described intrapsychic struggles $(n=60), 27.6 \%$ of the sample described divine struggles $(n=35)$, and $18.9 \%$ described both types of struggles $(n=24){ }^{5}$ According to the content analysis, several themes for each type of struggle.

\section{Content Analyses}

Four types of divine struggles were identified from participants’ descriptions. These included: strains in the relationship with God; feelings of abandonment, punishment, or being unheard by God; questioning God's actions in response to personal situations and in response to global situations. The first theme, feeling strains in the relationship with the divine, was described by $36.7 \%$ of people writing about divine struggles $(n=22)^{6}$. The strains ranged from feelings of isolation and loneliness to feelings of anger. For example, one participant reported feeling "lonely and distant from God.” Another participant wrote about feelings elicited by the death of a loved one: "When my grandma died, I was really mad at God for taking her away from me and my family.” Another participant experienced both anger and loneliness: “... when things don't turn out the way I wanted them to, I don’t blame myself, I blame God. When that happens, it makes me feel more angry at myself and at god, because I don’t ask specifically for His help, but I feel like he could have intervened a bit. I just get so angry

\footnotetext{
${ }^{5}$ Eight participants' responses to this question were unable to be content analyzed due to ambiguous or unclear responses. Therefore, $n$ for the content analysis is 119, not 127.

${ }^{6}$ Frequencies were calculated using the frequency that each theme was endorsed. 59 participants described divine struggles, with one participant describing two types of divine struggles. Therefore, $n=60$, will be used when calculating frequencies of each theme.
} 
and lonely...” Another individual reported "a sense of frustration, [because] no matter how hard I try I'm not as close to God as I should be.”

Feelings that God has forsaken, punished, or has not listened, was the second most common theme, articulated by $31.7 \%(n=19)$ of participants experiencing a divine struggle. One individual described recent negative events as being a punishment by God: "All these bad things started happening in my life and to my friends and it felt like God wasn't there and could have prevented these things from happening. It almost felt like punishment for something.” Another participant wrote about the impact of unanswered prayers: "I feel as if God does not either listen or respond to things that I pray for with all my heart and it causes more confusion into my life...” Other participants discussed feeling forsaken by God. For example, "Sometimes I have wondered if what I have been doing is not what God wants me to be doing... Or that what I have worked so hard on is not up to God's approval because I am shot down," and "I sometimes think that God hates me, or has abandoned me. I'm not really sure why I feel this way, but I do.”

The other types of divine struggles described by the sample included questioning God's action, because of personal situations $(18.3 \%, n=11)$ or because of global suffering $(8.3 \%, n=5)$ situations. For the former theme, one individual described how deaths of loved ones caused questions about God's actions: "My spiritual struggle started when I lost my best friend due to a fatal heart attack...and 6 months later I lost my grandma due to an illness. I don’t understand God's reasoning when he takes young people from loved ones, and why he does it the way he does." Another individual described confusion about perceived incongruence between God's nature and actions: "I was in a verbally abusive relationship with a guy in high school. I was doubting if God 
was there for me and if He loved me so much, why was he letting this happen.” For doubts caused by global situations, one respondent said, “I just get confused, because I don't understand that $\mathrm{i}[\mathrm{f}]$ there really is someone up there watching over us why so many bad things happen in our lives.”. Another individual stated, “...I am struggling with the idea of why God can let bad things happen to good people if he has the control and power to stop them from happening.”

With respect to participants' descriptions of intrapsychic spiritual struggles, five themes emerged: uncertainty regarding one’s personal belief system; questioning God’s existence; questioning religious scriptures or political ideology of their religion; questions about personal actions in relation to religious beliefs; and an internal struggle between wanting to believe, but not being able to.

Uncertainty regarding personal beliefs was the most frequently endorsed intrapsychic theme $(38.2 \%, n=34)^{7}$. Within this theme, some individuals described their struggle in the context of their upbringing. For example, one individual reported, "I was never raised in a religious home so I just don't understand all the views people have and am not sure where I fit in.” Another individual explained, “Both of my parents have separate religious beliefs. My mother being Christian and my dad being Muslim. Both have fed me their views which has caused the confusion and has started many hypothesis of my own about religion.” One individual wondered “...if I was Christian...only because my parents were Christian...” Other participants reported that their struggle arose in the context of interacting with others: "everyone else around me has different beliefs than me. So whenever they start talking about it I feel like maybe I'm wrong and

\footnotetext{
${ }^{7}$ Frequencies were calculated using the frequency that each intrapsychic theme was endorsed. 84 participants described intrapsychic struggles, with five participants describing two themes. Therefore, $n=$ 89, will be used when calculating frequencies of each theme.
} 
they are right.” Lastly, one individual demonstrated how struggles can exist even in the midst of a strong religious belief, "I have a pretty strong relationship with God, but I sometimes have questions about my belie[fs] and my religion.”

Twenty-two percent of individuals describing an intrapersonal struggle questioned God’s existence $(22.5 \%, n=20)$. For example, “I do not always know if I believe in God or that He really exists", and “I struggle knowing whether there is an above power influencing the way that I am floating through the world.” Other individuals reported wanting proof about God's existence: “Its just hard to believe that there is a God, when your questions aren't answered, you've never saw him, and especially when things get tough.” and "I feel that there is a God but I would like some proof.” Another individual reported questioning God's existence, in spite of feeling blessed: “Its not that I think God has abandoned me-He (if he exists) has blessed me a lot throughout my life. However, I am having major doubts about whether or not He really exists.”

Struggling with scriptures or with ideology and political beliefs of their religion/church was endorsed by $18 \%$ of individuals describing intrapsychic struggles ( $n$ =16). Some individuals reported struggles specifically about the reliability of religious scriptures, such as "How am I supposed to know if everything in the Bible is from God...," and "I find it hard to take the Bible word for word and with discoveries in science it becomes harder to believe many of the stories in the Old Testament especially.” Other individuals discussed struggling with the ideology of their religion. For example, "My spiritual struggle began when I first started identifying myself as a homosexual. My spiritual struggle seems so complicated to me. I find it hard to have a sturdy relationship with God, when the Bible says how I live my life is wrong,” and “I...don’t believe 
everything that the Bible says, and that makes me feel like I'm a bad Christian because I’m going against the Bible sometimes. I just think that the Christian religion should be modernized/updated to today’s time...” One individual described struggling with the church’s political stances “My spiritual struggle started with the last election, and many of the issues that were brought up. My church did not support many of the same issues that I did.”

The next theme centered on the individual's internal struggle between personal actions and religious beliefs. This type of intrapersonal struggle was endorsed by $12.4 \%$ of this sample $(n=11)$. Some individuals felt guilty about not participating in religious activities: "My spiritual struggle is feeling guilty about not going to church. Even though I try to do devotions each night, it is hard for me because I tend to find excuses or I forget about doing them, and then I feel guilty.” Others indicated feeling guilty about not following all the practices of their religion: "I do not agree with everything God says is right and wrong. Not agreeing and following his rules exactly makes me feel guilty and question myself. I get confused and frustrated.” Other participants reported struggling with incongruence between their actions and God’s desires: "Sometimes I have wondered if what I have been doing is not what God wants me to be doing...," and "My spiritual struggle started when I first began to become more active in my faith. I realized that I was doing many things wrong that hurt my relationship with God. I struggle spiritually with sin that keeps recurring in my life...this causes me guilt and makes me distant from God.”

The last category of intrapersonal struggles describes an internal struggle about wanting to believe in religion, but not being able to $(5.6 \%, n=5)$. One participant 
expressed a desire to believe that God existed, "I want to believe in the fairy tale of God but there is too much bad in the world to have a benevolent/omnipotent God that is there...” One individual described her struggles about wanting to believe, “...As much as I wish I could fully commit myself to being a Christian and follow the teachings, it is hard for me to believe fully. I mean, I can say that I believe in everything, but I really don't, and you cant make yourself no matter how hard you try...I feel like maybe God is punishing me in the ultimate way- by making me question him or feel like there is nothing I can do to feel fully committed to God.”

\section{Changes over time}

At follow-up, on the self-report outcome item, the majority of participants reported that their struggles were at least partially resolved (partially resolved $=53.5 \%, n$ $=68$; completely resolved $=3.1 \%, n=4)$. Forty percent $(n=52)$ reported no change in their struggle. Only three participants (2.4\%) reported an intensification of their struggle. Additionally, based on the single item question assessing outcome, nearly half of the sample indicated growing from their struggle $(48.8 \%, n=62)$ and roughly a quarter (26.8\%, $n=34$ ) reported experiencing both growth and decline. The rest of the sample reported either no change $(21.3 \%, n=27)$ or decline $(3.1 \%, n=4)$. The outcomes, "grow” and “decline”, were intentionally ambiguous, allowing the participant to interpret and respond to the terms as they saw fit. To clarify what participants meant by their responses to the question, they were asked to explain their response. These free-responses provided meaningful descriptive information about the impact that the struggles had on participants. Based on these descriptions, participants experienced growth religiously and personally. For example, participants indicated several types of religious growth, such as 
a stronger relationship with God and engagement in more religious activities. Participants also indicated that struggles affected them intrapersonally as well. For example, some participants indicated that they had developed a stronger identity and become more mature as a result of their struggle. Participants also indicated a variety of decline outcomes. Some indicated increased guilt because of incongruence between personal religious beliefs and actions, whereas others indicated growing spiritually, but becoming more fearful or confused.

Changes in outcome measures substantiated the participant's perceptions of growth. In general, scores on criterion measures indicated that the sample was less distressed at follow-up than at baseline. First, scores on the NRCOPE decreased significantly from baseline to follow-up $(t(126)=3.03, p<.01)$. Similar decreases occurred on the individual subscales of the NRCOPE. Specifically, Spiritual Dissatisfaction, Punishing God Appraisals, and “New” items (items added to ask about specific dimensions of intrapsychic and divine struggles) all significantly decreased from baseline to follow-up $(t(126)=4.10, p<.001, t(126)=3.04, p<.01$, and $t(126)=3.86$, $p<.001$, respectively). Additionally, scores on several criterion measures demonstrated that the sample was less distressed at time two than at time one. Scores on the BSI ( $t$ $(126)=5.0, p<.001)$ and Spiritual Decline $(t(126)=2.63, p<.01)$ scales significantly decreased from baseline to follow-up. Scores on the PTGI $(t(126)=4.73, p<.001)$ and SWLS $(t(126)=-2.16, p<.05)$ increased significantly, indicating more secular growth and satisfaction with life. Spiritual Growth was the only criterion measure that did not significantly change over time $(t(126)=-1.81, p=.07)$. 


\section{Correlational Analyses}

\section{Correlates of Growth}

Pearson bivariate correlations were calculated for predictor category and the criterion measures indicative of growth at time two (i.e., Posttraumatic Growth Inventory, Satisfaction with Life, Spiritual Growth, and Resolvability). Results are presented in Table 3.

Posttraumatic Growth. Within the struggle characteristics category, finding meaning and struggle severity were associated with posttraumatic growth. Specifically, finding meaning from the struggle was related to more posttraumatic growth $(r=.36, p<$ .001). Struggle severity was also associated with posttraumatic growth: the more severe the struggle, the greater the posttraumatic growth $(r=.26, p<.01)$.

Next, positive religious coping was significantly related to this criterion measure $(r=.18, p<.05)$. Of the four subscales, only Religious Purification $(r=.26, p<.01)$ and Spiritual Connection $(r=.19, p<.05)$ were associated with posttraumatic growth.

Specifically, increases in these subscales were associated with increases in posttraumatic growth. The remaining predictor categories, religious history and support, were not significantly related to post-traumatic growth.

Satisfaction with Life. Individual variables from struggle characteristics, religious history, and support categories were all significantly related to satisfaction with life. Specifically, from the struggle characteristics category, struggle severity was related to decreased satisfaction with life $(r=-.20, p<.05)$; whereas finding meaning was related to increased satisfaction with life $(r=.19, p<.05)$. For religious history, avoidant 
attachment was the only variable significantly associated with satisfaction with life. Specifically, this attachment style was related to decreases in satisfaction with life $(r=-$ $.19, p<.05)$. For the support category, secular support and religious support from God were significantly related to this criterion. Total secular support, support from significant others, and support from friends were all associated with increased satisfaction with life ( $r=.26, p<.01 ; r=.27, p<.01$; and $r=.18, p<.05$, respectively). Religious support from God was associated with increased life satisfaction $(r=.20, p<.05)$. Positive religious coping was not significantly related to satisfaction with life.

Spiritual Growth. Spiritual growth was significantly correlated with variables from each predictor category. For struggle characteristics, ability to find meaning in one’s struggle was significantly related to increased spiritual growth $(r=.49, p<.001)$. Struggle severity, however, was not significantly related to spiritual growth.

Three variables from religious history, secure attachment, avoidant attachment, and religious integration, were related to spiritual growth. Specifically, a secure attachment was related to increased spiritual growth $(r=.38, p<.001)$. Avoidant attachment was related to decreased spiritual growth $(r=-.45, p<.001)$. Greater integration of religion into one's life was associated with increased spiritual growth $(r=$ $.42, p<.001)$.

From the support category, only religious support was significantly related to spiritual growth. Greater perceptions of total religious support were related to more spiritual growth $(r=.39, p<.001)$. Similarly, both subtypes of religious support were linked to greater spiritual growth: congregational support $(r=.29, p<.001)$ and support from God $(r=.45, p<.001)$. Positive Religious Coping was also related to increased 
spiritual growth $(r=.41, p<.001)$, as well as each of the PRCOPE subscales: Benevolent Religious Reappraisals: $r=.29, p<.01$; Collaborative Coping $r=.36, p<.001$; Religious Purification: $r=.38, p<.001$; and Spiritual Connection: $r=.30, p<.001$ ).

Resolvability. Individual variables from each predictor category were significantly related to resolvability. First, from struggle characteristics, finding meaning was positively related to resolvability $(r=.36, p<.001)$. From religious history, secure attachment style and religious integration were associated with greater resolvability: $r=$ $.22, p<.05$ and $r=.30, p<.001$, respectively. For the support category, total religious support $(r=.30, p<.001)$, congregational $(r=.24, p<.01)$, and God $(r=.30, p=.001)$, were consistently related to increased resolvability. The last category, positive religious coping was also significantly associated with resolvability. The entire scale, PRCOPE, and the subscales Benevolent Religious Reappraisals, Collaborative Coping, Religious Purification, and Spiritual Connection were all related to greater resolvability $(r=.34, p$ $<.001, r=.25, p<.01, r=.27, p<.01, r=.32, p<.001$, and $r=.30, p<.001$, respectively).

\section{Correlates of Decline}

Pearson bivariate correlations were calculated for predictor categories and criterion measures indicative of decline at time two (i.e., global distress and spiritual decline). Results are presented in Table 4.

Global Distress. Distress was significantly associated with variables from each predictor category. Within the struggle characteristics category, greater struggle severity was related to increased distress $(r=.43, p<.001)$. Religious history variables, specifically avoidant and secure attachment styles, were also related to general distress. 
Avoidant attachment was related to more distress $(r=.26, p<.01)$, while secure attachment was related to less distress $(r=-.22, p<.05)$. From the support category, total secular support and religious support from God was associated with decreased distress ( $r$ $=-.19, p<.05$ and $r=-.21, p<.05$, respectively). Lastly, for the positive religious coping category, Religious Purification was significantly associated with increased distress ( $r=$ $.18, p<.05)$.

Spiritual Decline. Spiritual decline was also significantly associated with each predictor category. For struggle characteristics, struggle severity and ability to find meaning were significantly related to spiritual decline. Increased severity of the struggle was related to more spiritual decline $(r=.19, p<.05)$. Finding meaning was related to less spiritual decline $(r=-.24, p<.001)$.

Within the religious history category, secure attachment, avoidant attachment, and religious integration were all significantly correlated with spiritual decline. Secure attachment was related to lower spiritual decline $(r=-.40, p<.001)$. The opposite relationship was found for avoidant attachment: Increases in avoidant attachment were associated with more spiritual decline $(r=.49, p<.001)$. Religious integration was also related to less spiritual decline $(r=-.42, p<.001)$.

For the support category, religious support was related to less spiritual decline ( $r$ $=-.38, p<.001)$. This relationship was consistent for both of the subscales:

congregational: $r=-.26, p<.01$ and God: $r=-.51, p<.001$. Similar results were found for positive religious coping: More positive religious coping was related to less spiritual decline ( $r=-.40, p<.001)$, which was also true for most of the subscales: Benevolent 
Religious Reappraisals: $r=-.32, p<.001$, Collaborative Coping $r=-.42, p<.001$, and Religious Purification: $r=-.34, p<.001$.

\section{Hierarchical Multiple Regression Analyses}

Hierarchical multiple regression equations were generated for each predictor category. Since the demographic variables were not significantly related to predictor variables, two-step regression equations were only constructed for criterion measures in which change between time one and time two was assessed (i.e., Satisfaction with Life and BSI, or global distress). For the two-step regression equations, time one scores of the outcome measure were entered into the first step and the individual predictors were then entered into the second step. For Posttraumatic Growth Inventory, Spiritual Growth, and Spiritual Decline, controlling for change between time one and time two was not meaningful because these measures specifically asked about changes since the struggle. The last criterion measure, resolvability, was only assessed at time two, therefore change for this outcome was not assessed. Separate regression analyses were conducted for the individual variables from each predictor category. Individual predictors that added significant variance were identified and beta coefficients were calculated. A final regression equation was then calculated for each criterion measure using the significant predictor variables identified through the earlier regression analyses involving the specific categories of predictors. These results are discussed below and are presented in Tables 5 through 8 .

Predictors of Growth Outcomes

Predictors of posttraumatic growth. Two of the four predictor categories significantly accounted for variance in posttraumatic growth. Struggle characteristics 
(refer to table 5a) and religious coping (refer to table 5b) added unique contributions to the prediction of posttraumatic growth. Struggle characteristics accounted for $17 \%$ of variance in this outcome $\left(R^{2}=.17, p<.001\right)$. Within this category, meaning and struggle severity were significantly predictive of post-traumatic growth $(\beta=.34, p<.001$ and $\beta=$ $.24, p<.01$, respectively). Positive Religious Coping accounted for $6.7 \%$ of unique variance in growth $\left(R^{2}=.067, p<.05\right)$. Religious Purification coping was the only significant predictor from this category $(\beta=.35, p<.01)$.

A final regression equation (refer to table 5c) was constructed using the three significant variables, struggle severity, meaning, and Religious Purification. This model predicted $20 \%$ of variance in posttraumatic growth $\left(R^{2}=.20, p<.001\right)$. All of these variables remained significant predictors in the final equation (i.e., struggle severity, $\beta=$ $.20, p<.05$; meaning $\beta=.33, p<.001$; and Religious Purification, $\beta=.19, p<.05$ )

Predictors of satisfaction with life. Two-step hierarchical regression equations were constructed for this criterion measure. Specifically, ratings of satisfaction with life were entered into the first step for all regression equations. This step, satisfaction with life at time one, predicted $39.7 \%$ of variance for this criterion measure $\left(R^{2}=.397, p<\right.$ .001). The subsequent regression equations controlled for this finding. None of the categories significantly predicted satisfaction with life after controlling for time one scores.

Predictors of spiritual growth. Struggle characteristics, religious history, support, and religious coping accounted for significant proportions of variance in spiritual growth. Struggle characteristics (refer to table 6a) predicted $26 \%$ of unique variance in spiritual growth $\left(R^{2}=.26, p<.001\right)$. Within this category, meaning and struggle severity were 
significant predictors of unique variance in spiritual growth, with struggle severity related to decreased spiritual growth ( $\beta=.50, p<.001 ; \beta=-.16, p<.05$, respectively). Religious history (refer to table $6 \mathrm{~b})$, predicted $27 \%\left(R^{2}=.27, p<.001\right)$ of unique variance in spiritual growth. In this category, avoidant attachment and religious integration were both significant predictors of growth, though in different directions $(\beta=-.30, p<.01 ; \beta=.29$, $p=.001$, respectively). Specifically, avoidant attachment was a significant predictor of decreased spiritual growth while religious integration was a predictor of increased spiritual growth. With respect to the support category (refer to table 6c), support significantly predicted $20 \%$ of the variance in spiritual growth $\left(R^{2}=.20, p<.001\right)$. Religious support from God was the only significant predictor within this category ( $\beta=$ $.39, p<.001$ ). The last category, religious coping (table $6 \mathrm{~d}$ ), significantly accounted for $17 \%$ of unique variance for this criterion measure $\left(R^{2}=.17, p<.001\right)$. Collaborative Religious Coping was the only significant predictor of spiritual growth $(\beta=.26, p<.05)$.

A final regression equation (table 6e) was constructed using the significant variables from each category. These variables were: struggle severity, finding meaning, religious integration, avoidant attachment, religious support from God, and Collaborative Religious Coping. The final regression equation accounted for $46 \%$ of unique variance in spiritual growth $\left(R^{2}=.46, p<.001\right)$. Four of six variables, struggle severity $(\beta=-.17, p<$ $.05)$, finding meaning $(\beta=.44, p<.001)$, avoidant attachment $(\beta=-.35, p<.001)$, and religious integration $(\beta=.18, p<.05)$ were significant predictors of this outcome. Specifically, struggle severity and avoidant attachment were significant predictors of unique variance in declines in spiritual growth, while finding meaning and religious integration were predictive of increased spiritual growth. 
Predictors of resolvability. Each category significantly predicted resolvability of the struggle. The first equation was constructed for struggle characteristics (table 7a). These variables accounted for $11 \%$ of variance in resolvability $\left(\Delta R^{2}=.11, p<.001\right)$. The only significant predictor of this outcome was ability to find meaning in the struggle ( $\beta=.36$, $p<.001$ ). The religious history category (table $7 \mathrm{~b}$ ) accounted for $9 \%$ of the variance for resolvability $\left(R^{2}=.09, p<.01\right)$. Religious integration emerged as a significant predictor of resolvability $(\beta=.27, p<.01)$. The support category (table $7 \mathrm{c}$ ) was also a significant predictor of resolvability, accounting for $6 \%$ of variance $\left(R^{2}=.06, p<.05\right)$. Religious support from God was the only significant predictor of resolvability from this category ( $\beta$ $=.24, p<.05$ ). The last category, religious coping (table $7 \mathrm{~d}$ ), accounted for $11 \%$ of unique variance in resolvability $\left(R^{2}=.11, p=.001\right)$; however, none of the specific religious coping types was a significant predictor of resolvability.

A final regression equation (table 7e) was constructed using the significant variables from the above equations: meaning, religious integration, and support from God. This equation accounted for $18 \%$ of unique variance in resolvability $\left(R^{2}=.18, p<\right.$ .001). Of these variables, only meaning emerged a significant predictor $(\beta=.29, p=$ $.001)$.

Predictors of Distress Outcomes.

Predictors of global distress. Two-step hierarchical regression equations were constructed for global distress. The first step, global distress at time one, accounted for $55.2 \%$ of variance in time two distress $\left(R^{2}=.552 p<.001\right)$. Individual predictors from each category were entered into the second step. None of the categories were significant predictors of distress at time two. 
Predictors of spiritual decline. The regression equation for struggle characteristics (table 8a) accounted for $8.7 \%$ of unique variance in spiritual decline $\left(R^{2}=.087, p<.001\right)$. Both individual variables, struggle severity and finding meaning, were significant predictors. Struggle severity was a significant predictor of more spiritual decline, while finding meaning was a predictor of less decline $(\beta=.21, p<.05$ and $\beta=-.26, p<.01$, respectively). The variables from the religious history category (table 8b) predicted 29\% of variance in the criterion $\left(R^{2}=.29, p<.001\right)$. Avoidant attachment style significantly predicted more spiritual decline and religious integration significantly predicted less spiritual decline ( $\beta=.36, p=.001 ; \beta=-.27, p<.01$, respectively). The third equation, constructed with variables from the support category (table $8 \mathrm{c}$ ), predicted $24 \%$ of unique variance in spiritual decline $\left(\Delta R^{2}=.24, p<.001\right)$. Only religious support from God was a significant predictor, specifically less spiritual decline $(\beta=-.49, p<.001)$. The last equation was constructed with variables from the religious coping category (table 8d). This regression equation accounted for $17 \%$ of unique variance for spiritual decline $\left(R^{2}=\right.$ $.17, p<.001)$. Collaborative Religious Coping was the only significant predictor from this category, predicting less spiritual decline $(\beta=-.31, p<.01)$.

A final regression equation (table 8e) was constructed with the significant variables from each of the predictor categories. These variables included: struggle severity, avoidant attachment, religious integration, religious support from God, and Collaborative Religious Coping. The entire regression equation accounted for 34\% of unique variance in spiritual decline $\left(R^{2}=.34, p<.001\right)$. Struggle severity and avoidant attachment emerged as significant predictors of increased spiritual decline $(\beta=.19, p<$ 
$.05 ; \beta=.29, p<.01$, respectively) and religious integration emerged as significant predictor of less spiritual decline ( $\beta=-.22, p<.05$, respectively). 


\section{DISCUSSION}

The purpose of this study was to identify and differentiate between pathways associated with growth and decline following a spiritual struggle. Previous research has focused on identifying predictors and outcomes of spiritual struggles. These studies have linked spiritual struggles to indices of both psychological and physical decline and psychological growth. The question remains, however, what factors determine whether struggles lead to decline and/or growth? This study attempted to answer this question by focusing on a group of college students who were experiencing spiritual struggles and then examining a set of variables that might predict whether the students experienced positive or negative outcomes 4 to 6 weeks later. Four predictor categories were identified from existing theory and research about traumatic life events: struggle characteristics, religious history, support, and religious coping. Variables from each category were identified that would help differentiate between pathways leading to growth and decline. Specifically, it was hypothesized that struggle characteristics, struggle severity and finding meaning, would be associated with growth. For the religious history category, it was predicted that religious integration and secure attachment would be tied to more growth while avoidant and anxious attachment would be tied to more decline. Religious and secular support variables were hypothesized to be predictors of growth. Lastly, use of positive religious coping methods was expected to relate to growth. In general, the results of this study supported these hypotheses. This study investigated both secular and spiritual dimensions of growth and decline. Secular outcomes included life satisfaction, posttraumatic growth, and global dissatisfaction; spiritual outcomes included spiritual growth, struggle resolution, and spiritual decline. 
In the following sections, the results of this study are discussed in more detail. The written comments by the participants in this study are also used to illustrate and elaborate upon the findings. The limitations of the study are then considered. Finally, the implications of the study and future directions for research are addressed.

\section{Correlational Findings}

Correlational findings provided initial information about the factors associated with growth and decline following spiritual struggles. Generally, the predictors were related to growth or decline outcomes in the expected ways, with a few noteworthy exceptions. These findings are organized and discussed by the four predictor categories.

\section{Struggle Characteristics}

Struggle severity and finding meaning were related to secular and religious outcomes, though not always in expected directions. Specifically, it was hypothesized that struggle severity would be related to growth outcomes. Interestingly, this variable was related to indices of growth and decline. With respect to growth, severity was related to increased posttraumatic growth; with respect to decline, severity was related to decreased life satisfaction, increased global distress, and increased spiritual decline. Although existing research has not investigated the relationship between spiritual struggle severity and outcome, studies investigating traumatic events have demonstrated that increased event severity is related to increased growth (e.g., Brennan, 2002; Tedeschi \& Calhoun, 1996). Based on these studies, it was presumed that the severity of spiritual struggles would act the same way: that severe spiritual struggles would be related to more growth. How do we explain the relationships between struggle severity and decline? Previous research has demonstrated that the relationship between event severity and 
growth follows an "inverted U” pattern, with moderately severe events relating to increased growth (Fontana \& Rosenheck, 1998). Although participants’ reported moderate levels of struggle severity $(M=32.83$, scale range $=15-60)$, it is possible that spiritual struggles are inherently more severe for individuals than other struggles. Struggling with something that is central to one’s life, namely spirituality, is arguably more distressing than struggling with an external event. In fact, research has found that the more integral or central a struggle is to one's life, the more difficult it is to integrate the experience (Tait \& Cohen Silver, 1989). Additionally, spiritual struggles are a sign that the religious orientation system is in distress. To review, the religious orientation system is a general guide that influences and helps mobilize religious resources during turbulent times (Pargament, 1997). If this orientation system is strained, individuals may be left with limited resources to help assimilate the spiritual struggle. Difficulties with assimilating new experiences, even distressing ones, may lead to decline.

Focusing on the ability to find meaning, the results of this study were more straightforward and consistent with expectations. People who found more meaning in their struggle reported greater posttraumatic growth, life satisfaction, spiritual growth, struggle resolution, and less spiritual decline. A few descriptions of struggle outcome illustrate the meaning and benefits participants derived from their struggles. One participant reported general growth as a result of the struggle: "I have found many positives in the struggle...” Another individual described struggles as a tool that God uses to encourage growth: "I feel like I have come to know better how God uses struggles to show us his glorious ways in the end.” These findings are consistent with existing literature. Finding meaning from negative life events, such as the death of a loved one 
and the diagnosis of HIV, has been linked with better physical health, increased wellbeing, and decreased depression (e.g.,, Farber, Mirsalimi, Williams, \& McDaniel, 2003; Murphy, Johnson, \& Lohan, 2003; Thompson, 1991).

Religion offers individuals with a structure and a mechanism to find meaning in their lives (e.g., Park, 2005). When the structure that provides meaning is shaken, it is logical that being able to find meaning can help to restore this structure. Moreover, the need for meaning is a powerful motivation; indeed, some argue that it is fundamental to humanity (Frankl, 1946), making it even more important to be able to restore a framework of meaning when it has been shaken.

\section{Religious History}

Although there are many factors that contribute to an individual's religious history, this study focused on two factors: attachment to God and religious integration. Both of these components of religious history had implications for the outcome of a spiritual struggle.

Research has linked secure attachment to God with better outcomes, and avoidant and anxious attachments with poorer outcomes (Belavich \& Pargament, 2000; Kirkpatrick \& Shaver, 1992; \& Rowatt \& Kirkpatrick, 2002). Based on these findings, it was hypothesized that secure attachment would be related to growth following spiritual struggles, while avoidant and anxious attachments would be related to decline. Results from this study generally supported this prediction: secure attachment was related to growth and avoidant attachment was related to decline. Specifically, secure attachment was related to increased spiritual growth, greater struggle resolution, less global distress, and lower spiritual decline; avoidant attachment was related to increased global distress, 
greater spiritual decline, decreased life satisfaction, and increased spiritual growth. A secure attachment is one factor that strengthens the religious orientation system (Pargament, 1997; Weinborn, 1999). This attachment may help mobilize resources that are needed to integrate the struggle experience. Drawing on past experiences with God may help individuals with secure attachments endure and make sense of these periods of strain. However, individuals who described an impersonal, cold, and distant relationship with God would not have the same past experiences to draw from. Conceivably, their past history might only make their experiences worse. Consistent with this possibility, individuals with avoidant attachments in this study were more likely to decline.

As predicted, religious integration was related to growth, specifically spiritual growth and struggle resolution. Religious integration refers to the degree to which an individual's religion is incorporated into other areas of his/her life. For example, an individual with poor religious integration would compartmentalize religion, separating religious beliefs and practices out from other aspects of life. Literature on traumatic life events supports the notion that religious integration is associated with better outcomes (e.g., McIntosh, Silver, \& Wortman, 1993; Park, Cohen, \& Murch, 1996). However, studies focusing on individuals experiencing spiritual struggles have found a different pattern of findings. These studies suggest that religious integration is tied to greater distress for individuals experiencing spiritual struggles (Kooistra \& Pargament, 1999; Pargament, Tarakeshwar, Ellison, \& Wulff, 2001). Although the studies investigating spiritual struggles are more relevant to the present study, it was hypothesized that individuals with greater religious integration would experience growth following their spiritual struggle. This hypothesis was based on the idea that, although struggles might be 
initially more distressing for individuals with greater integration, after some time, greater integration would facilitate the mobilization of resources as it did for individuals experiencing traumatic life events. Results from this study provides support for this assertion, demonstrating that religious integration was related to increased spiritual growth and struggle resolution. Thus, increased religious integration may help mobilize resources, allowing individuals to assimilate and accommodate their experiences.

\section{Support}

It was hypothesized that secular and religious support would be associated with different types of positive outcomes. The results of this study provided support for this hypothesis: secular support was associated with secular growth, while religious support was related to both secular and spiritual growth.

Looking first at secular support, previous research has shown that secular support is an important resource for individuals experiencing a variety of negative life events (e.g., Cadell, Rogeher, \& Hemsworth, 2003; Lesserman et al., 1999, and Shen, McCreary, \& Myers, 2004). Results from this study are consistent with the previous research: secular support was related to increased life satisfaction. It is interesting to note that secular support was not associated with any religious outcomes. Perhaps secular support is a resource that affects individuals in secular dimensions of life, without crossing into religious dimensions. A study looking at the different relationships of secular and religious support on religious coping strategies provides support for this assertion (Krause, Ellison, Shaw, Marcum, \& Boardman, 2001). In this study, the relationship of emotional support from congregation, religious support from congregation, and emotional support from pastor on use of religious resources, namely 
religious coping, was investigated. Emotional support from congregation members was not associated with use of religious coping; however, religious support (defined as religious support from congregation and emotional support from pastor) was associated with increased use of religious coping.

With respect to religious support, people who reported receiving more religious support during their spiritual struggles were more likely to experience secular and spiritual growth. Based on these findings, it seems that there are important benefits for people receiving religious support during spiritual struggles. These findings are consistent with research on religious support (e.g., Maton, 1989; Krause, Ellison, Shaw, Marcum, \& Boardman, 2001). Of particular relevance is Maton’s (1989) study that investigated the relationship between spiritual support and emotional well-being in a sample of adults suffering from a recent loss of a loved one and college students that faced three or more uncontrollable stressors. Results demonstrated that spiritual support was related to psychological well-being, specifically lower depression and higher selfesteem for adults, and greater emotional well-being for college students. These results suggest that individuals benefit from turning to religious resources during periods of spiritual concern as well.

One additional point of interest is the beneficial nature of receiving support from God. Although more than half of the sample described experiencing tension in their relationship with God (e.g.,, feelings of anger, abandonment, punishment in relation to God), support from God was related to better life satisfaction, struggle resolution, and spiritual growth. This underscores the importance of having an on-going relationship with 
God. In spite of tensions with God, people who were still able to turn to God for support were able to experience growth outcomes.

\section{Positive Religious Coping}

The last predictor category, positive religious coping, was comprised of four different types of religious coping: benevolent religious reappraisals, collaborative religious coping, spiritual connection, and religious purification. Consistent with the hypothesis, these coping strategies were generally related to secular and religious growth. These results were consistent with previous research that has demonstrated the general benefits associated with positive religious coping methods (see Pargament, 1997 for a review). Interestingly, religious purification had mixed implications: it was associated with increased growth and increased global distress. A review of studies investigating religious coping techniques found similar results for religious purification (see Pargament, 1997). Religious purification is a style of coping in which individuals engage in religious activities to gain spiritual peace and cleansing (Pargament, Koenig, Perez, 2000). For individuals experiencing a spiritual struggle, engaging in religious activities may help reorient them with the sacred; however, engaging in religious activities alone is not enough. Individuals may need to change behaviors as well. Looking at the items for the religious purification subscale, 4 of 10 deal with the concept of sin, seeking repentance for past sin, or asking God for help in abstaining from sin. Individuals may feel more at peace and experience spiritual growth by engaging in religious activities. However, they may experience distress by recognizing and admitting that their behaviors are sinful. Several participants described these feelings. For example, one participant wrote, "I struggle spiritually with sin that keeps reoccurring in my life. I deal with sexual 
sin. This causes me guilt and makes me distant from God. It also make(s) me question myself in relation to my beliefs and religion.” Another individual wrote more generally about difficulty abstaining from sin, "Being a college student with temptations at hand almost always, religious conflict can happen often because you are forced to make the right choices or sin. Sometimes you ultimately make the wrong choice because most of the time it is the easier decision.” For these individuals, the dissonance between religious beliefs and personal choices elicits feelings of guilt and distress. On one hand, engaging in religious activities may make an individual feel better spiritually. On the other hand, it may heighten the dissonance between religious beliefs and practices, leading to more guilt and distress.

\section{Regression Findings}

Because the predictors of growth and decline following spiritual struggle were intercorrelated, regression analyses were conducted to identify the best independent predictors of growth and decline. Turning first to pathways leading to decline, avoidant attachment and struggle severity emerged as significant unique predictors of spiritual decline. The role that these variables have in weakening the religious orientation system may explain these results. First, individuals with an avoidant attachment to God have a distant, impersonal, and cold relationship with the divine. This relationship offers little comfort or safety for individuals. Individuals with this type of attachment may be more cautious and hesitant when exploring and learning from new situations because they would not have a safe haven to draw strength from (Kirkpatrick, 1992; Pargament, 1997). Thus, an avoidant attachment may compromise the ability of the orientation system to navigate through new experiences. The same logic applies to spiritual struggles: 
individuals with an avoidant attachment would have difficulty accommodating the struggle because they would not have a secure base of experiences to draw from. Second, increased struggle severity may reflect a weakened religious orientation system (Pargament, Murray-Swank, Magyar, Ano, 2003). With a compromised orienting system, an individual may be lost in the face of the struggle, and may not be able to access resources he/she would typically use to help integrate this experience. With a weakened guiding system and limited access to coping resources, these individuals may be more likely to decline.

Conversely, a strong religious orientation system may be predictive of growth. Results from this study support this notion: religious purification, religious integration, and finding meaning, factors associated with a stronger orientation system, were each uniquely predictive of a variety of growth outcomes. First, stronger religious orientation systems are associated with greater mobilization of religious resources during stressful live experiences (Pargament, 1997). Arguably then, individuals reporting more religious coping methods, such as religious purification, have a stronger orientation system. In this study, religious purification was predictive of growth, specifically posttraumatic growth. Second, incorporating religion into most, if not all, dimensions of life is another sign of a stronger orientation system (Pargament, 1997). Having a more integrated belief system provides individuals with a more cohesive orientation system. Without this unification, the religious orientation system would not be as helpful in navigating through difficult times. Additionally, greater religious integration may facilitate the mobilization of resources during times of stress, which would be related to better accommodation and assimilation of stressful experience. Lastly, religious orientation systems help individuals 
understand and make sense of the world (Pargament, 1997). Individuals with stronger orientation systems may be more likely to find meaning in their struggle. Meaning was the last, and arguably the strongest, individual predictor of growth. This variable was predictive of posttraumatic growth, spiritual growth, and struggle resolution. Moreover, meaning was the only significant predictor of struggle resolution. Struggle resolution represents the ultimate endpoint: successful integration of the struggle into the religious belief system. One potential reason why meaning may be such a robust variable is the nature of the struggle. Religious beliefs have been said to "be the most unfailing way to make meaning from...experiences,” (Park, 2005, p. 304). Being able to find meaning in the struggle would seem to restore the religious belief system. These three variables, religious purification coping, religious integration, and finding meaning, were all significant independent predictors of growth outcomes in this study. Moreover, each variable is associated with a stronger orientation system.

Based on these findings, then, there is preliminary evidence that a stronger religious orientation system is predictive of growth outcomes following spiritual struggles.

Interestingly, however, struggle severity was also related to growth, posttraumatic growth. This was the only variable predictive of unique variance for decline and growth outcomes. How can struggle severity, which is viewed as a burden to the orientation system, also relate to growth? To explain this finding, we first have to look at the criterion that spiritual struggle severity was related to. Within the religious domain, struggle severity was related to decline (spiritual decline); within the secular domain, struggle severity was related to growth (posttraumatic growth). Based on these findings, it appears that spiritual struggles have different implications for secular and spiritual 
domains of life. Within the secular world, a severe struggle may shake the worldview, leaving the potential for secular growth. However, it is possible that the same spiritual struggle has more negative implications for the individual's spiritual world. Struggling with something that is at the core of the spiritual world may shatter, not just shake, this dimension of life, therefore leading to spiritual decline. 


\section{LIMITATIONS}

To date, this study is the first to clarify the pathways leading between spiritual struggles, growth, and decline. Several limitations of this study, however, have to be considered.

First, the study sample was restricted. College students were the focus of attention here. Whether the same predictors would generalize to an adult sample remains to be determined. Nevertheless, a college student sample may be appropriate when investigating spiritual struggles because college is a time of transition between adolescence and adulthood. During this time, individuals develop and start to solidify their belief systems. Moreover, spiritual struggles are relatively common among college students, with roughly half of this group experiencing spiritual struggles at any given time (Johnson \& Hayes, 2003). Second, the sample was restricted based on the demographics of participants. The sample was predominately female (71.7\%) and was predominately affiliated with Christian or Catholic traditions (83.4\%). It is important to investigate whether similar findings would emerge from studies of males and people across different religious traditions.

Another major limitation was the nature of the assessment tools. The study was based on individual's self-reports and response bias could not be controlled. It is possible that the results reflect a social desirability bias. However, this possibility may be tempered somewhat by the fact that people completed the measures anonymously in the study. After the initial screening, participants did not have direct contact with the experimenter and they were able to complete the surveys at their convenience. Moreover, research suggests that individuals report honestly on measures similar to the ones used in 
this study. For example, the Posttraumatic Growth Inventory (which was used in this study to assess secular growth) was not correlated with social desirability, as measured by the Marlow-Crowe Social Desirability Scale (Tedeschi \& Calhoun, 1996). Lastly, participants were asked about and endorsed experiencing positive and negative outcomes. Arguably, if they were attempting to present themselves in a positive light or trying to reconstruct the past few weeks through rose-tinted glasses, they would not have endorsed negative outcomes. Regardless, in the future, studies should incorporate scales assessing for social desirability, controlling for it if necessary.

Another limitation involves the assessment of change through the measures in this study. Specifically, participants were asked about their perceptions of change in several of the outcome measures. Asking individuals to reflect on change introduces another layer of subjectivity and interpretation. Research on the Stress-Related Growth Scale, a scale assessing for change after stressful life experiences, provides evidence that argues against this limitation (Park, Cohen, \& Murch, 1996). During the initial development and validation of this scale, the authors obtained individual's perceptions of change as well as those of outside observers (close family and friends). The subjects’ perceptions were modestly correlated with the outside observers' ratings, suggesting that subjects are not biased when reflecting on changes in their lives. Additionally, the authors argue that perceptions of change may be more important in the aftermath of a stressful or traumatic event. Traumatic events can cause changes in one's life philosophy. These philosophical changes may impact an individual's life in meaningful way, but may not be observable from the outside. Instead of relying solely on an outside rater's perception of change, 
future studies could use physiological measures to substantiate an individual's reports of change. 


\section{DIRECTIONS FOR FUTURE RESEARCH}

Despite the limitations of the current study, these findings have implications for future research, both basic and applied. In terms of basic research, this study contributes to an initial understanding of the pathways leading to growth and decline following spiritual struggles. However, many questions remain unanswered. First, are there other variables that predict outcome following a struggle? Specifically, how does the notion that pathways to growth and decline are largely determined by the strength of one's orientation system hold up? To address this, variables relating to the strength of the orientation system should be investigated. Four factors, religious integration, flexibility, differentiation, and benevolence, are linked with stronger orientation systems (Pargament, 1997; Weinborn, 1999). The current study focuses on two of these factors, religious integration and benevolence (operationalized as attachment to God). Variables assessing the flexibility and the differentiation of religious beliefs may also have implications for the outcome of spiritual struggles. Second, this study focused on divine and intrapersonal spiritual struggles. Future studies should investigate interpersonal spiritual struggles. Specifically, determining whether the predictors identified here apply to interpersonal struggles would be an important next step. Consistent with other literature on this field, this study investigated a primarily Caucasian, Christian sample. Future research should expand this, investigating whether these findings generalize to samples that are more diverse.

Another important question is whether these predictors can be used to identify individuals at risk for declines following a spiritual struggle. Although these predictors have been identified from a sample experiencing spiritual struggles, it would be 
important to see if, using these profiles, we could successfully predict the outcome an individual would experience after a struggle. With this information, religious leaders, clinicians, and other helping professionals, may be able to intervene before individuals decline. Moreover, equipped with the knowledge of this study, helping professionals may be able to develop interventions aimed at encouraging growth for individuals experiencing spiritual struggles. Spiritual struggles represent an orientation system in flux, and being able to intervene can help make this experience positive and helpful, rather than negative and harmful. 


\section{CONCLUSIONS}

In conclusion, this study adds to the existing literature on spiritual struggles. Research has shown that spiritual struggles can lead to both decline and growth. This study shed some light on the factors that may determine whether struggles are beneficial or destructive. Based on these findings, it appears that there are some distinctions between pathways of growth and decline. Specifically, finding meaning, religious integration, secure attachment to God, support, and religious coping techniques were related to growth, and avoidant attachment was related to decline outcomes. Two variables, struggle severity and religious purification coping, were pathways to growth and decline. Generally, it seems that variables that strengthen the religious orientation systems are predictive of growth, while variables that weaken the system are predictive of decline. There were several limitations to this study, including the nature of the sample and possibility for self-report bias. Despite these limitations, the current study provides valuable information about predictors of growth and decline subsequent to spiritual struggles. 


\section{TABLES}

Table 1: Variables Assessed at Each Timepoint

\begin{tabular}{|c|c|c|}
\hline Screening & Time One & Time Two \\
\hline Assessment of & Struggle & \\
\hline Intrapsychic Struggle & Intrapsychic Struggle & \\
\hline Divine Struggle & Divine Struggle & \\
\hline \multirow[t]{27}{*}{ Negative RCOPE } & Negative RCOPE & Negative RCOPE \\
\hline & Predictor & Variables \\
\hline & $\frac{\text { Struggle Characteristics }}{\text { Struggle Severity }}$ & $\begin{array}{l}\text { Struggle Characteristics } \\
\text { Resolvability } \\
\text { Meaning }\end{array}$ \\
\hline & $\underline{\text { Religious History }}$ & \\
\hline & $\begin{array}{l}\text { Religious Integration } \\
\text { Attachment Style }\end{array}$ & \\
\hline & $\underline{\text { Support }}$ & \\
\hline & Secular Support & \\
\hline & -from friends & \\
\hline & -from family & \\
\hline & -from significant other & \\
\hline & Religious Support & \\
\hline & -from congregation & \\
\hline & $\begin{array}{l}\text {-from God } \\
\text { Religious Coping }\end{array}$ & \\
\hline & Benevolent Religious & \\
\hline & Reappraisal & \\
\hline & Collaborative Religious & \\
\hline & Coping & \\
\hline & Spiritual Connection & \\
\hline & Religious Purification & \\
\hline & Outcome & Variables \\
\hline & Posttraumatic Growth & Posttraumatic Growth \\
\hline & Satisfaction with Life & Satisfaction with Life \\
\hline & Spiritual Growth & Spiritual Growth \\
\hline & Global Distress & Global Distress \\
\hline & Spiritual Decline & Spiritual Decline \\
\hline & & Resolvability \\
\hline & & Self-Reported Outcome \\
\hline
\end{tabular}

Notes: Measures in left column were assessed at screening; measures in middle column were assessed at time one; measures in right column were assessed at time two. 
Table 2a: Descriptive Information and Internal Consistencies for Time One Measures

\begin{tabular}{|c|c|c|c|c|c|}
\hline Scale & $\mathrm{M}$ & SD & Potential Range & Actual Range & \\
\hline NRCOPE & 63.09 & 19.4 & $32-136$ & $35-117$ & .96 \\
\hline Spiritual & 6.84 & 2.63 & $4-16$ & 4-15 & .80 \\
\hline Dissatisfaction & & & & & \\
\hline $\begin{array}{l}\text { Punishing God } \\
\text { Appraisals }\end{array}$ & 3.30 & 1.42 & $2-8$ & $2-7$ & .71 \\
\hline New Items & 22.99 & 6.84 & $11-44$ & $12-41$ & .86 \\
\hline IES & 32.83 & 9.33 & $15-60$ & $15-52$ & .88 \\
\hline Attachment & 13.69 & 1.35 & $9-18$ & $11-18$ & .78 \\
\hline Secure & 4.19 & 1.15 & $3-6$ & $3-6$ & .70 \\
\hline Avoidant & 4.03 & 1.23 & $3-6$ & $3-6$ & .83 \\
\hline Anxious & 4.85 & 1.05 & $3-6$ & $3-6$ & .58 \\
\hline Religious & & & & & \\
\hline Integration & 14.54 & 4.23 & $6-24$ & $6-24$ & .80 \\
\hline $\begin{array}{l}\text { Social Support } \\
\text { Significant }\end{array}$ & 47.86 & 8.35 & $12-60$ & $23-60$ & .90 \\
\hline Other & 16.14 & 3.71 & $4-20$ & $6-20$ & .92 \\
\hline Family & 15.56 & 3.60 & $4-20$ & $5-20$ & .85 \\
\hline Friends & 16.16 & 3.20 & $4-20$ & $7-20$ & .89 \\
\hline \multicolumn{6}{|l|}{ Religious } \\
\hline Support & 67.95 & 15.16 & $21-105$ & $27-105$ & .94 \\
\hline Congregation & 21.70 & 5.97 & $7-35$ & 7-35 & .91 \\
\hline God & 24.62 & 5.67 & $7-35$ & $7-35$ & .87 \\
\hline $\begin{array}{l}\text { PRCOPE } \\
\text { Collaborative }\end{array}$ & 70.27 & 18.44 & $30-120$ & $35-105$ & .95 \\
\hline $\begin{array}{l}\text { Religious } \\
\text { Coping } \\
\text { Benevolent } \\
\text { Religious }\end{array}$ & 19.65 & 5.26 & $8-32$ & $8-30$ & .86 \\
\hline $\begin{array}{l}\text { Appraisals } \\
\text { Religious }\end{array}$ & 20.91 & 6.30 & $9-36$ & $9-34$ & .89 \\
\hline $\begin{array}{l}\text { Purification } \\
\text { Spiritual }\end{array}$ & 22.67 & 8.15 & $10-40$ & $10-39$ & .94 \\
\hline Connection & 7.04 & 2.55 & $3-12$ & $3-12$ & .83 \\
\hline PTGI & 70.41 & 20.98 & $19-114$ & $19-112$ & .95 \\
\hline BSI & 34.61 & 14.48 & $17-85$ & $17-67$ & .94 \\
\hline
\end{tabular}




\begin{tabular}{lccccc}
\hline SWLS & 21.91 & 7.04 & $5-35$ & $5-35$ & .86 \\
Spiritual Growth & 19.56 & 6.30 & $5-35$ & $6-35$ & .86 \\
Spiritual Decline & 18.32 & 6.88 & $5-35$ & $5-34$ & .85 \\
\hline
\end{tabular}


Table 2b: Descriptive Information and Internal Consistencies for Time Two Measures

\begin{tabular}{lrrlll}
\hline \multicolumn{1}{c}{ Scale } & M & SD & Potential Range & Actual Range & $\alpha$ \\
\hline $\begin{array}{l}\text { NRCOPE } \\
\quad \text { Spiritual }\end{array}$ & 58.94 & 18.42 & $34-136$ & $36-115$ & .96 \\
$\quad \begin{array}{l}\text { Dissatisfaction } \\
\text { Punishing God }\end{array}$ & 6.02 & 2.34 & $4-16$ & $4-15$ & .82 \\
$\quad \begin{array}{l}\text { Appraisals } \\
\text { New Items }\end{array}$ & 2.99 & 1.25 & $2-8$ & $2-7$ & .72 \\
Meaning & 21.00 & 6.58 & $11-44$ & $12-43$ & .88 \\
PTGI & 2.18 & .74 & $1-4$ & $1-4$ & N/A \\
BSI & 61.88 & 20.49 & $19-114$ & $19-114$ & .95 \\
SWLS & 30.27 & 12.40 & $17-85$ & $17-66$ & .93 \\
Spiritual Growth & 20.64 & 6.70 & $5-35$ & $8-35$ & .85 \\
Spiritual Decline & 16.80 & 7.46 & $5-35$ & $5-35$ & .90 \\
Resolvability & 2.57 & .59 & $1-4$ & $5-33$ & .89 \\
\hline
\end{tabular}


Table 3: Correlations between Predictor and Growth Outcome Measures at Time Two

\begin{tabular}{|c|c|c|c|c|}
\hline & $\begin{array}{l}\text { Posttraumatic } \\
\text { Growth }\end{array}$ & $\begin{array}{l}\text { Satisfaction } \\
\text { with Life }\end{array}$ & $\begin{array}{l}\text { Spiritual } \\
\text { Growth }\end{array}$ & Resolvability \\
\hline \multicolumn{5}{|l|}{ Struggle } \\
\hline \multicolumn{5}{|l|}{ Characteristics: } \\
\hline IES & $.26 \mathrm{~b}$ & $-.20 \mathrm{a}$ & -.13 & .02 \\
\hline Meaning & $.36 \mathrm{c}$ & $.19 a$ & $.49 \mathrm{c}$ & $.36 \mathrm{c}$ \\
\hline \multicolumn{5}{|l|}{$\underline{\text { Religious }}$} \\
\hline \multicolumn{5}{|l|}{ History: } \\
\hline \multicolumn{5}{|l|}{ Attachment } \\
\hline Avoidant & .01 & $-.19 \mathrm{a}$ & $-.45 c$ & -.17 \\
\hline Secure & .06 & .11 & $.38 \mathrm{c}$ & $.22 \mathrm{a}$ \\
\hline Anxious & .16 & -.05 & .02 & .08 \\
\hline Religious & .08 & .01 & $.42 \mathrm{c}$ & $.30 \mathrm{c}$ \\
\hline \multicolumn{5}{|l|}{ Integration } \\
\hline \multicolumn{5}{|l|}{ Support: } \\
\hline Secular Support & .07 & $.26 b$ & .02 & .04 \\
\hline \multicolumn{5}{|l|}{ Others } \\
\hline Family & .04 & .17 & -.06 & .01 \\
\hline Friends & .09 & $.18 \mathrm{a}$ & .02 & .01 \\
\hline \multicolumn{5}{|l|}{ Religious } \\
\hline Support & .07 & .12 & $.39 c$ & $.30 \mathrm{c}$ \\
\hline Congregation & .04 & .09 & $.29 c$ & $.24 \mathrm{~b}$ \\
\hline God & .05 & $.20 \mathrm{a}$ & $.45 c$ & $.30 \mathrm{c}$ \\
\hline \multicolumn{5}{|l|}{$\underline{\text { Religious }}$} \\
\hline \multicolumn{5}{|l|}{ Coping: } \\
\hline PRCOPE & $.18 \mathrm{a}$ & -.02 & $.41 \mathrm{c}$ & $.34 \mathrm{c}$ \\
\hline Benevolent & .12 & .03 & $.29 c$ & $.25 b$ \\
\hline \multicolumn{5}{|l|}{ Religious } \\
\hline \multicolumn{5}{|l|}{ Reappraisal } \\
\hline Collaborative & -.01 & .101 & $.36 \mathrm{c}$ & $.27 \mathrm{~b}$ \\
\hline \multicolumn{5}{|l|}{ Religious } \\
\hline \multicolumn{5}{|l|}{ Coping } \\
\hline Religious & $.26 b$ & -.09 & $.38 c$ & $.32 \mathrm{c}$ \\
\hline Purification & & & & \\
\hline Spiritual & $.19 a$ & -.13 & $.30 \mathrm{c}$ & $.30 \mathrm{~b}$ \\
\hline
\end{tabular}

Notes: a: $\mathrm{p}<.05$, b: $\mathrm{p}<.01 ; \mathrm{c}: \mathrm{p}<.001$ 
Table 4: Correlations between Predictor and Decline Outcome Measures at Time Two

\begin{tabular}{|c|c|c|}
\hline & Global Distress & Spiritual Decline \\
\hline \multicolumn{3}{|l|}{ Struggle } \\
\hline \multicolumn{3}{|l|}{ Characteristics: } \\
\hline IES & $.43 c$ & $.19 a$ \\
\hline Meaning & -.05 & $-.24 b$ \\
\hline \multicolumn{3}{|l|}{ Religious History: } \\
\hline \multicolumn{3}{|l|}{ Attachment } \\
\hline Avoidant & $.26 b$ & $.49 c$ \\
\hline Secure & $-.22 \mathrm{a}$ & $-.40 c$ \\
\hline Anxious & .13 & .02 \\
\hline Religious & -.09 & $-.42 c$ \\
\hline \multicolumn{3}{|l|}{ Integration } \\
\hline \multicolumn{3}{|l|}{ Support: } \\
\hline Secular Support & $-.19 a$ & -.06 \\
\hline Significant Others & -.16 & -.10 \\
\hline Family & -.14 & .018 \\
\hline Friends & -.16 & -.64 \\
\hline Religious Support & -.14 & $-.38 c$ \\
\hline Congregation & -.11 & $-.26 b$ \\
\hline God & $-.21 \mathrm{a}$ & $-.51 c$ \\
\hline \multicolumn{3}{|l|}{ Religious Coping: } \\
\hline PRCOPE & .07 & $-.40 c$ \\
\hline Benevolent & .04 & $-.32 c$ \\
\hline Religious & & \\
\hline Reappraisal & & \\
\hline Collaborative & -.01 & $-.42 c$ \\
\hline Religious Coping & & \\
\hline Religious & $.18 a$ & $-.34 c$ \\
\hline Purification & & \\
\hline Spiritual & .07 & -.17 \\
\hline Connection & & \\
\hline
\end{tabular}

Notes: a: $\mathrm{p}<.05$, b: $\mathrm{p}<.01 ; \mathrm{c}: \mathrm{p}<.001$ 
Table 5a: Regression Equation for Prediction of Posttraumatic Growth by Struggle Characteristics

\begin{tabular}{|l|l|l|}
\hline Predictor Category: & Adjusted $\mathrm{R}^{2}$ & Beta \\
\hline Struggle Characteristics & $.17 \mathrm{c}$ & \\
\hline IES & & $.24 \mathrm{~b}$ \\
\hline Meaning & & $.34 \mathrm{c}$ \\
\hline
\end{tabular}

Notes: a: $\mathrm{p}<.05$, b: $\mathrm{p}<.01$; $\mathrm{c}: \mathrm{p}<.001$ 
Table 5b: Regression Equation for Prediction of Posttraumatic Growth by Religious Coping

\begin{tabular}{|l|l|l|}
\hline Predictor Category: & Adjusted $\mathrm{R}^{2}$ & Beta \\
\hline Religious Coping & $.07 \mathrm{a}$ & \\
\hline Benevolent Religious Reappraisals & & -.06 \\
\hline Collaborative & & -.18 \\
\hline Spiritual Connection & & .06 \\
\hline Religious Purification & & $.35 \mathrm{~b}$ \\
\hline
\end{tabular}

Notes: a: $\mathrm{p}<.05$, b: $\mathrm{p}<.01$; $\mathrm{c}: \mathrm{p}<.001$ 
Table 5c: Final Regression Equation for Prediction of Posttraumatic Growth by Significant Variables From each Category of Predictors

\begin{tabular}{|l|l|l|}
\hline & Adjusted $\mathrm{R}^{2}$ & Beta \\
\hline Significant Variables: & $.20 \mathrm{c}$ & \\
\hline IES & & $.20 \mathrm{a}$ \\
\hline Meaning & & $.33 \mathrm{c}$ \\
\hline Purification & & $.19 \mathrm{a}$ \\
\hline
\end{tabular}

Notes: a: $\mathrm{p}<.05$, b: $\mathrm{p}<.01$; $\mathrm{c}: \mathrm{p}<.001$ 
Table 6a: Regression Equation for Prediction of Spiritual Growth by Struggle Characteristics

\begin{tabular}{|l|l|l|}
\hline Predictor Category: & Adjusted $\mathrm{R}^{2}$ & Beta \\
\hline Struggle Characteristics & $.26 \mathrm{c}$ & \\
\hline IES & & $-.16 \mathrm{a}$ \\
\hline Meaning & & $.50 \mathrm{c}$ \\
\hline
\end{tabular}

Notes: a: $\mathrm{p}<.05$, b: $\mathrm{p}<.01 ; \mathrm{c}: \mathrm{p}<.001$ 
Table 6b: Regression Equation for Prediction of Spiritual Growth by Religious History

\begin{tabular}{|l|l|l|}
\hline Predictor Category: & Adjusted $\mathrm{R}^{2}$ & Beta \\
\hline Religious History & $.27 \mathrm{c}$ & \\
\hline Secure Attachment & & .09 \\
\hline Anxious Attachment & & .12 \\
\hline Avoidant Attachment & & $-.30 \mathrm{~b}$ \\
\hline Integration & & $.29 \mathrm{c}$ \\
\hline
\end{tabular}

Notes: a: $\mathrm{p}<.05, \mathrm{~b}: \mathrm{p}<.01 ; \mathrm{c}: \mathrm{p}<.001$ 
Table 6c: Regression Equation for Prediction of Spiritual Growth by Support

\begin{tabular}{|l|l|l|}
\hline Predictor Category: & Adjusted $\mathrm{R}^{2}$ & Beta \\
\hline Support & $.20 \mathrm{c}$ & \\
\hline Significant Other & & .09 \\
\hline Friends & & -.06 \\
\hline Family & & -.11 \\
\hline Congregational & & .27 \\
\hline God & & $.39 \mathrm{c}$ \\
\hline
\end{tabular}

Notes: a: $\mathrm{p}<.05$, b: $\mathrm{p}<.01 ; \mathrm{c}: \mathrm{p}<.001$ 
Table 6d: Regression Equation for Prediction of Spiritual Growth by Religious Coping

\begin{tabular}{|l|l|l|}
\hline Predictor Category: & Adjusted R $^{2}$ & Beta \\
\hline Religious Coping & $.17 \mathrm{c}$ & \\
\hline Benevolent Religious Reappraisals & & -.10 \\
\hline Collaborative Coping & & $.26 \mathrm{~b}$ \\
\hline Spiritual Connection & & -.17 \\
\hline Religious Purification & & .22 \\
\hline
\end{tabular}

Notes: a: $\mathrm{p}<.05$, b: $\mathrm{p}<.01$; $\mathrm{c}: \mathrm{p}<.001$ 
Table 6e: Final Regression Equation for Prediction of Spiritual Growth by Significant Variables from Each Category of Predictors

\begin{tabular}{|l|l|l|}
\hline & Adjusted $\mathrm{R}^{2}$ & Beta \\
\hline All Significant Variables & $.46 \mathrm{c}$ & \\
\hline IES & & $-.17 \mathrm{a}$ \\
\hline Meaning & & $.44 \mathrm{c}$ \\
\hline Avoidant Attachment & & $-.35 \mathrm{c}$ \\
\hline Religious Integration & & $.18 \mathrm{a}$ \\
\hline Collaborative & & .05 \\
\hline God & & -.01 \\
\hline
\end{tabular}

Notes: a: $\mathrm{p}<.05$, b: $\mathrm{p}<.01$; $\mathrm{c}: \mathrm{p}<.001$ 
Table 7a: Regression Equation for Prediction of Resolvability by Struggle Characteristics

\begin{tabular}{|l|l|l|}
\hline Predictor Category & Adjusted $\mathrm{R}^{2}$ & Beta \\
\hline Struggle Characteristics & $.11 \mathrm{c}$ & \\
\hline IES & & .01 \\
\hline Meaning & & $.36 \mathrm{c}$ \\
\hline
\end{tabular}

Notes: a: $\mathrm{p}<.05$, b: $\mathrm{p}<.01$; $\mathrm{c}: \mathrm{p}<.001$ 
Table 7b: Regression Equation for Prediction of Resolvability by Religious History

\begin{tabular}{|l|l|l|}
\hline Predictor Category: & Adjusted $\mathrm{R}^{2}$ & Beta \\
\hline Religious History & $.09 \mathrm{~b}$ & \\
\hline Secure Attachment & & .16 \\
\hline Anxious Attachment & & .14 \\
\hline Avoidant Attachment & & .03 \\
\hline Integration & & $.27 \mathrm{~b}$ \\
\hline
\end{tabular}

Notes: a: $\mathrm{p}<.05$, b: $\mathrm{p}<.01$; $\mathrm{c}: \mathrm{p}<.001$ 
Table 7c: Regression Equation for Prediction of Resolvability by Support

\begin{tabular}{|l|l|l|}
\hline Predictor Category: & Adjusted $\mathrm{R}^{2}$ & Beta \\
\hline Support & $.06 \mathrm{a}$ & \\
\hline Significant Other & & .06 \\
\hline Friends & & -.07 \\
\hline Family & & -.02 \\
\hline Congregational & & .16 \\
\hline God & & $.24 \mathrm{a}$ \\
\hline
\end{tabular}

Notes: a: $\mathrm{p}<.05$, b: $\mathrm{p}<.01$; $: \mathrm{p}<.001$ 
Table 7d: Regression Equation for Prediction of Resolvability by Religious Coping

\begin{tabular}{|l|l|l|}
\hline Predictor Category: & Adjusted $\mathrm{R}^{2}$ & Beta \\
\hline Religious Coping & $.11 \mathrm{~b}$ & \\
\hline Benevolent Religious Reappraisals & & -.06 \\
\hline Collaborative & & .17 \\
\hline Spiritual Connection & & .21 \\
\hline Religious Purification & & .14 \\
\hline
\end{tabular}

Notes: a: $\mathrm{p}<.05$, b: $\mathrm{p}<.01$; $\mathrm{c}: \mathrm{p}<.001$ 
Table 7e: Final Regression Equation for Prediction of Resolvability by Significant Variables from each Category of Predictors

\begin{tabular}{|l|l|l|}
\hline & Adjusted $\mathrm{R}^{2}$ & Beta \\
\hline Significant Variables & $.18 \mathrm{c}$ & \\
\hline Meaning & & $.29 \mathrm{~b}$ \\
\hline Integration & & -.14 \\
\hline God & & .17 \\
\hline
\end{tabular}

Notes: a: $\mathrm{p}<.05$, b: $\mathrm{p}<.01$; $\mathrm{c}: \mathrm{p}<.001$ 
Table 8a: Regression Equation for Prediction of Spiritual Decline by Struggle Characteristics

\begin{tabular}{|l|l|l|}
\hline Predictor Category: & Adjusted $\mathrm{R}^{2}$ & Beta \\
\hline Struggle Characteristics & $.09 \mathrm{~b}$ & \\
\hline IES & & $.21 \mathrm{a}$ \\
\hline Meaning & & $-.26 \mathrm{~b}$ \\
\hline
\end{tabular}

Notes: a: $\mathrm{p}<.05$, b: $\mathrm{p}<.01 ; \mathrm{c}: \mathrm{p}<.001$ 
Table 8b: Regression Equation for Prediction of Spiritual Decline by Religious History

\begin{tabular}{|l|l|l|}
\hline Predictor Category: & Adjusted $^{2}$ & Beta \\
\hline Religious History & $.29 \mathrm{c}$ & \\
\hline Secure Attachment & & .06 \\
\hline Anxious Attachment & & .08 \\
\hline Avoidant Attachment & & $.36 \mathrm{~b}$ \\
\hline Integration & & $-.27 \mathrm{~b}$ \\
\hline
\end{tabular}

Notes: a: $\mathrm{p}<.05$, b: $\mathrm{p}<.01$; $\mathrm{c}: \mathrm{p}<.001$ 
Table 8c: Regression Equation for Prediction of Spiritual Decline by Support

\begin{tabular}{|l|l|l|}
\hline Predictor Category: & Adjusted $\mathrm{R}^{2}$ & Beta \\
\hline Support & $.24 \mathrm{c}$ & \\
\hline Significant Other & & -.03 \\
\hline Friends & & .02 \\
\hline Family & & .06 \\
\hline Congregational & & -.22 \\
\hline God & & $-.49 \mathrm{c}$ \\
\hline
\end{tabular}

Notes: a: $\mathrm{p}<.05$, b: $\mathrm{p}<.01$; $\mathrm{c}: \mathrm{p}<.001$ 
Table 8d: Regression Equation for Prediction of Spiritual Decline by Religious Coping

\begin{tabular}{|l|l|l|}
\hline Predictor Category: & Adjusted $\mathrm{R}^{2}$ & Beta \\
\hline Religious Coping & $.17 \mathrm{c}$ & \\
\hline Benevolent Religious Reappraisals & & -.08 \\
\hline Collaborative Coping & & $-.31 \mathrm{~b}$ \\
\hline Religious Purification & & -.15 \\
\hline Spiritual Connection & & .04 \\
\hline
\end{tabular}

Notes: a: $\mathrm{p}<.05$, b: $\mathrm{p}<.01 ; \mathrm{c}: \mathrm{p}<.001$ 
Table 8e: Final Regression Equation for Prediction of Spiritual Decline by Significant Variables from each Category of Predictors

\begin{tabular}{|l|l|l|}
\hline & Adjusted $\mathrm{R}^{2}$ & Beta \\
\hline All Significant Variables & $.34 \mathrm{c}$ & \\
\hline IES & & $.19 \mathrm{a}$ \\
\hline Avoidant Attachment & & $.29 \mathrm{~b}$ \\
\hline Integration & & $-.22 \mathrm{a}$ \\
\hline God & & -.15 \\
\hline Collaborative & & -.05 \\
\hline
\end{tabular}

Notes: $\mathrm{a}: \mathrm{p}<.05, \mathrm{~b}: \mathrm{p}<.01 ; \mathrm{c}: \mathrm{p}<.001$ 


\section{REFERENCES}

Allport, G.W. (1950). The individual and his religion: A psychological interpretation. Oxford, England: Macmillan Press.

American Psychological Association. (2000). Diagnostic and statistical manual of mental disorders ( $4^{\text {th }}$ ed., text revised). Washington, DC: Author.

Antonucci, T.B. \& Israel, B.A. (1986). Veridicality of social support: A comparison of principal and network members' responses. Journal of Consulting and Clinical Psychology, 54, 432-437.

Batson, C.D., Schoenrade, P., \& Ventis, W.L. (1993). Religion and the Individual: A social-psychological approach. Oxford, England: University Press.

Belavich, T.G. \& Pargament, K.I. (2002). The role of attachment in predicting spiritual coping with a loved on in surgery. Journal of Adult Development, 9, 13-29.

Brennan, M. (2002). Spirituality and psychosocial development in middle-age and older adults with vision loss. Journal of Adult Development, 9, 31-46.

Cadell, S., Regeher, C., \& Hemsworth, D. (2003). Factors contributing to posttraumatic growth: A proposed structural equation model. American Journal of Orthopsychiatry, 73, 279-287.

Chalfant, H. P., Heller, P. L., Roberts, A., Briones, D., Aguirre-Hochbaum, S., \& Farr, W. (1990). The clergy as a resource for those encountering psychological distress. Review of Religious Research, 31, 305-313.

Derogatis, L.R. \& Spencer, P.M. (1975). The brief symptom inventory: Administration, scoring, and procedures manual. Baltimore, MD: Johns Hopkins University, School of Medicine. 
Diener, E., Emmons, R.A., Larsen, R.J., \& Griffen, S. (1985). The satisfaction with life scale. Journal of Personality Assessment, 49, 71-75.

Exline, J.J. (2003). Anger toward God: A brief overview of existing research.

Psychology of Religion Newsletter, 29, 1-7.

Exline, J.J., Yali, A.M., \& Sanderson, W.C. (2000). Guilt, discord, and alienation: The role of religious strain in depression and suicidality. Journal of Clinical Psychology, 56, 1481-1496.

Farber, E.W., Mirsalimi, H., Williams, K.A., \& McDaniel, S. (2003). Meaning of illness and psychological adjustment to HIV/AIDS. Psychosomatics, 44, 485-491.

Fiala, W.E., Bjorck, J.P., \& Gorush, R. (2002). The religious support scale: Construction, validation, and cross-validation. American Journal of Community Psychology, 30, 761-786.

Fitchett, G., Rybarczyk, B. D., DeMarco, G. A., \& Nicholas, J. J. (1999). The role of religion in medical rehabilitation outcomes: A longitudinal study. Rehabilitation Psychology, 44, 1-22.

Fontana, A. \& Rosenheck, R. (1998). Psychological benefits and liabilities of traumatic exposure in the war zone. Journal of Traumatic Stress, 11, 485-503.

Frazier, P., Berman, M., \& Steward, J. (2002). Perceived control and posttraumatic stress: A temporal model. Applied and Preventive Psychology, 10, 207-223.

Howoritz, M.J., Wilner, N., \& Alvarez, W. (1979). Impact of event scale: A measure of 
subjective stress. Psychosomatic Medicine, 41, 209-218.

Hunsberger, B., Pratt, M., \& Prancer, S.M. (2002). A longitudinal study of religious doubts in high school and beyond: Relationships, stability, and searching for answers. Journal for the Scientific Study of Religion, 41, 255-266.

Janoff-Bulman, R. (1992). Shattered assumptions: Towards a new psychology of trauma. New York, NY: Free Press.

Johnson, C.V. \& Hayes, J.A. (2003). Troubled spirits: Prevalence and predictors of religious and spiritual concerns among university students and counseling center clients. Journal of Counseling Psychology, 50, 409-419.

Kirkpatrick (1992). An attachment-theory approach to the psychology of religion. International Journal for the Psychology of Religion, 2(1), 3-28.

Kirkpatrick, L. \& Shaver, P.R. (1992). An attachment-theoretical approach to romantic love and religious belief. Society for Personality and Social Psychology, $18,266-275$.

Koenig, H.G., Pargament, K.I., \& Nielson, J. (1998). Religious coping and health status in medically ill hospitalized older adults. The Journal of Nervous and Mental Disease, 186, 266-275.

Kooistra, W. \& Pargament, K.I. (1999). Religious doubting in parochial school adolescents. Journal of Psychology and Theology, 27, 33-42.

Krause, N., Ellison, C.G., Shaw, B.A., Marcum, J.P., \&Boardman, J. (2001). Churchbased social support and religious coping. Journal for the Scientific Study of Religion, 40, 637-656.

Krause, N., Ellison, C.G., Wulff, K.M. (1998). Church-based support, negative 
interaction and psychological well-being: Findings from a national sample of Presbyterians. Journal for the Scientific Study of Religion, 37, 725-741.

Krause, N., Ingersoll-Dayton, B., Ellison, C. G., \& Wulff, K. M. (1999). Aging, religious doubt, and psychological well-being. The Gerontologist, 39, 525-533.

Lesserman, J., Jackson, E., Petitto, J., Golden, R., Silvia, S., Perkins, D., Gai, J., Folds, J., \& Evans, D. (1999). Progression to AIDS: The effects of stress, depressive symptoms, and social support. Psychosomatic Medicine, 61, 397-406.

Licht, M.H. (1996). Chapter 2: Multiple regression and correlation. In G.G. Grimm \& P.R. Yarnold (Eds.), Reading and Understanding Multivariate Statistics (pp. 1964). Washington, DC: American Psychological Association.

Maton, K.I. (1989). The stress-buffering role of spiritual support: Cross-sectional and prospective investigations. Journal for the Scientific Study of Religion, 28, 310323.

McIntosh, D., Silver, R.C., \& Wortman, C.B. (1993). Religion’s role in adjustment to a negative life event: Coping with the loss of a child. Journal of Personality and Social Psychology, 65, 812-821.

Murphy, S. A., Johnson, L. C., \& Lohan, J. (2003). Finding meaning in a child's violent death: A five-year prospective analysis of parents’ personal narratives and empirical data. Death Studies, 27, 381-404.

Neeson, L. (Narrator). (2001). What about God? [Television Series]. WGBH Video.

Nielsen, M. E. (1998). An assessment of religious conflicts and their resolutions. Journal for the Scientific Study of Religion, 37, 181-190.

Pargament (1997). The psychology of religion and coping: Theory, research, and 
practice. New York, NY: The Guilford Press.

Pargament, K. I., Ensing, D. S., Falgout, K., Olsen, H., Reilly, B., Van Haitsma, K., \& Warren, R. (1990). God help me (I): Religious coping efforts as predictors of the outcomes to significant negative life events. American Journal of Community Psychology, 18, 793-822.

Pargament, K.I., Koenig, H.G., \& Perez, L. (2000). The many methods of religious coping: Development and the initial validation of the RCOPE. Journal of Clinical Psychology, 54, 519-543.

Pargament, K.I., Koenig, H.G., Tarakershwar, N., \& Hahn, J. (2001). Religious struggle as a predictor of mortality among medically ill elderly patients. Arch Intern Med, 161, 1881-1885.

Pargament, K. I., Koenig, H. G., Tarakeshwar, N., \& Hahn, J. (2004). Religious coping methods as predictors of psychological, physical, and spiritual outcomes among medically ill elderly patients: A two-year longitudinal study. Journal of Health Psychology.

Pargament, K. I., Magyar, G. M., Benore, E., Mahoney, A. (2005). Sacrilege: A study of sacred loss and desecration and their implications for health and wellbeing in a community sample. Journal for the Scientific Study of Religion, 44, 5978.

Pargament, K.I, Murray-Swank, N., Magyar, G., \& Ano, G. (2005). Spiritual struggle: A phenomenon of interest to psychology and religion. In W. Miller \& H. Delaney (Eds.), Judeo-Christian perspectives on psychology: Human nature, motivation, and change. Washington DC: APA Press. 
Pargament, K. I., Silverman, W., Johnson, S., Echemendia, R., \& Snyder, S. (1983). The psychosocial climate of religious coping. American Journal of Community Psychology, 11, 351-381.

Pargament, K.I., Smith, B.W., Koenig, H.G., \& Perez, L. (1998). Patterns of positive and negative religious coping with major life stressors. Journal for the Scientific Study of Religion, 37, 710-724.

Pargament, K.I., Tarakeshwar, N., Ellison, C.G., \& Wulff, K.M. (2001). Religious coping among the religious: The relationships between religious coping and wellbeing in a national sample of Presbyterian clergy, elders, and members. Journal for the Scientific Study of Religion, 40, 497-513.

Pargament, K.I., Zinnbauer, B.J., Scott, A.B., Butter, E.M., Zerowin, J., \& Stanik, P. (1998). Red flags and religious coping: Identifying some religious warning signs among people in crisis. Journal of Clinical Psychology, 54, 77-89.

Park, C.L. (2005). Religion and Meaning. In R.F. Paloutzian \& C.L. Park (Eds.), Handbook of the psychology of religion and spirituality. New York: Guilford Press.

Park, C.L., Cohen, L.H., \& Murch, R.L. (1996). Assessment and prediction of stressrelated growth. Journal of Personality, 64, 71-105

Piaget, J. (1985). The equilibration of cognitive structures (T. Browth \& K.J. Thampy, Trans.). The University of Chicago Press, Chicago. (Original work published 1975).

Rowatt, W.C. \& Kirkpatrick, L.A. (2002). Two dimensions of attachment to God and 
their relation to affect, religiosity, and personality constructs. Journal for the Scientific Study of Religion, 41, 637-651.

Ryan, R.M., Rigby, S., \& King, K. (1993). Two types of religious internalization and their relations to religious orientations and mental health. Journal of Personality and Social Psychology, 65, 586-586.

Sarason \& Sarason (1994). Assessment of social support. In S.A. Shumaker \& S.M. Czajkowski (Eds.), Social support and cardiovascular disease (pp. 41-63). New York: Plenum Press.

Shen, B., McCreary, C.P., \& Myers, H.F. (2004). Independent and mediated contributions of personality, coping, social support, and depressive symptoms to physical functioning outcome among patients in cardiac rehabilitation. Journal of Behavioral Medicine, 27, 39-62.

Simpson, J.A. (2002). The ultimate elixir? Psychological Inquiry, 13, 226-229.

Smith, B. W., Pargament, K. I., Brant, C., \& Oliver, J. M. (2000). Noah revisited: Religious coping by church members and the impact of the 1993 Midwest flood. Journal of Community Psychology, 28, 169-186.

Tait \& Cohen Silver (1989). Coming to terms with major negative life events. In S. James \& J.A. Bargh (Eds.), Unintended thought, New York: Guilford Press.

Tedeschi, R.G. \& Calhoun, L.G. (1996). The posttraumatic growth inventory: Measuring the positive legacy of trauma. Journal of Traumatic Stress, 9 (3), $455-471$

Thompson, M.P., \& Vardman, P.J. (1997). The role of religion in coping with the loss of a family member to homicide. Journal for the Scientific Study of Religion, 36, 
44-51.

Thompson, S.C. (1991). The search for meaning following stroke. Basic and Applied Social Psychology, 12, 81-96.

Tillich, P. (1957). The dynamics of faith. New York: Harper and Row Publishers.

Trenholm, P., Trent, J., \& Compton, W.C. (1998). Negative religious conflict as a predictor of panic disorder. Journal of Consulting and Clinical Psychology,54, $59-65$.

Weinborn, M. (1999). A theoretical approach to the religion-mental health connection: Initial exploration of a religious orienting system. Unpublished doctoral dissertation, Bowling Green State University, Bowling Green.

Zimet, G.D., Dahlem, N.W., Zimet S.G., \& Farley, G.K. (1988). The multidimensional scale of perceived social support. Journal of Personality Assessment, 52, 30-41. 


\section{APPENDIX A. PREDICTOR MEASURES}

A-1 Informed Consent

A-2 Demographics and Assessment of Struggles

A-3 Struggle Characteristics (Impact of Event Severity and Finding Meaning)

A-4 God Attachment

A-5 Religious Integration

A-6 Secular Support

A-7 Religious Support

A-8 Positive Religious Coping 
Appendix A-1: Informed Consent

\section{Bowling Green State University}

Psychology Department

Bowling Green, Ohio 43403-0228

Phone: (419) 372-2301

FAX: (419) 372-6013

My name is Kavita Desai and I am a graduate student in the Psychology department at Bowling Green State University. This research study is being conducted for my thesis. The study will examine the types of spiritual struggles experienced by undergraduate students and the impacts these struggles have on an individual's life.

If you choose to participate, you will be asked to fill out two questionnaire that asks about religious, personal, and social beliefs and/or experiences. The first questionnaire will take approximately 60 minutes to complete. After about 4 weeks, I will contact you by e-mail asking you to fill out the second questionnaire, which will take about 30 minutes. If you participate in BOTH time points, you will receive 1.5 research credits. Participation in BOTH time points is required to obtain research credit.

All of your responses will be kept completely confidential. The information that you provide will not in any way be attached to your name. If using a public computer, you should not leave an incomplete questionnaire unattended. If an incomplete survey is left unattended, other individuals would be able to see your responses.

The risks of participating in this study are no greater than those normally encountered in daily life. This study is not expected to cause any extra or unusual emotional distress. However, if you express an interest in or feel a need for counseling I will provide you with information about the counseling services available on campus.

Your participation in this study is completely voluntary. You are free to withdraw consent and to discontinue participation in the study at any time.

By participating in this study, you will be helping psychologists and society better understand the complexities of religious life, including spiritual struggles. As a participant, you will benefit by learning more about how psychological research is conducted. Moreover, you will receive research credit for participation.

If you have any questions concerning this study, you can contact me, Kavita Desai, by e-mail at kdesai@bgnet.bgsu.edu or my advisor, Dr. Kenneth Pargament, by email at kpargam@bgnet.bgsu.edu. You can also contact the Human Subjects Review Board at BGSU by telephone, (419)372-7716, or by e-mail, hsrb@bgnet.bgsu.edu, if you have any questions about the rights as a research participant.

By clicking the "submit" button, you are indicating your consent to participate in this study. 
Appendix A-2: Demographics and Assessment of Spiritual Struggles

Please circle or fill in your responses.

1. Gender: MALE

FEMALE

2. Age:

3. Year in college:

$\begin{array}{llll}\text { Freshman } & \text { Sophomore } & \text { Junior } & \text { Senior }\end{array}$

4. Religious preference:

5. Current marital/relationship status:

Single Dating $\quad$ Married

Widow/Widower Separated/Divorced

Please circle the response that best fits you.

1. Currently, to what extent are you experiencing personal conflict regarding your religious beliefs, doubts about religion, or questions about God?

$\begin{array}{lllll}1 & 2 & 3 & 4 & 5 \\ \text { Not at all } & \text { A little bit } & \text { Moderately } & \text { Quite a bit } & \text { Extremely }\end{array}$

2. Currently, to what extent are you experiencing any tension in your relationship with God, such as confusion, anxiety, loneliness, frustration, anger, abandonment, or guilt?

$\begin{array}{lllll}1 & 2 & 3 & 4 & 5 \\ \text { Not at all } & \text { A little bit } & \text { Moderately } & \text { Quite a bit } & \text { Extremely }\end{array}$

If you answered 1, not at all, to question 1 AND 2, please skip questions 3-7, and begin with question 1 in the next section.

The feelings mentioned above can be referred to as a spiritual struggle. In question 6 when it asks about a spiritual struggle, it is referring to those feelings that you indicated experiencing in questions 1 and 2.

3. Approximately how long have you been experiencing these feelings? 
4. Have you ever experienced similar feelings in the past?

$$
\text { YES NO }
$$

5. If YES, how many times in the past?

6. Briefly describe how your spiritual struggle started, including the event(s) that triggered it.

7. Briefly describe your spiritual struggle, including what ideas, thoughts you are struggling with.

\section{Modified Negative RCOPE}

The following items deal with feelings that individuals may experience concerning their faith or their relationship with God and the distress that these feelings may cause. Using the scale below, please circle the number that best describes how much you are currently experiencing each item.

\section{I am currently...}

1. Wondering whether God has abandoned me. How much distress does this cause you?

$\begin{array}{cccc}\begin{array}{c}\text { Not At } \\ \text { All }\end{array} & \begin{array}{c}\text { Some- } \\ \text { what }\end{array} & \begin{array}{c}\text { Quite } \\ \text { A Bit }\end{array} & \begin{array}{c}\text { A Great } \\ \text { Deal }\end{array} \\ 0 & 1 & 2 & 3 \\ 0 & 1 & 2 & 3\end{array}$

2. Feeling punished by God for my lack of devotion. $\begin{array}{lllll}0 & 1 & 2 & 3\end{array}$ $\begin{array}{lllll}\text { How much distress does this cause you? } & 0 & 1 & 2 & 3\end{array}$

3. Wondering what I did for God to punish me. $\quad \begin{array}{lllll}0 & 1 & 2 & 3\end{array}$ $\begin{array}{lllll}\text { How much distress does this cause you? } & 0 & 1 & 2 & 3\end{array}$

4. Questioning God's love for me. $\quad \begin{array}{lllll}0 & 1 & 2 & 3\end{array}$ $\begin{array}{lllll}\text { How much distress does this cause you? } & 0 & 1 & 2 & 3\end{array}$

5. Questioning the power of God. $\quad \begin{array}{lllll}0 & 1 & 2 & 3\end{array}$ $\begin{array}{lllll}\text { How much distress does this cause you? } & 0 & 1 & 2 & 3\end{array}$

6. *Wondering if God really exists. $\quad \begin{array}{lllll}0 & 1 & 2 & 3\end{array}$ $\begin{array}{lllll}\text { How much distress does this cause you? } & 0 & 1 & 2 & 3\end{array}$ 
7. Feeling angry that God is not there for me. How much distress does this cause you?

$\begin{array}{llll}0 & 1 & 2 & 3 \\ 0 & 1 & 2 & 3\end{array}$

8. * Questioning if religious scriptures are really $\quad \begin{array}{llllll}0 & 1 & 2 & 3\end{array}$ the inspired word of God.

How much distress does this cause you? $\quad \begin{array}{lllll}0 & 1 & 2 & 3\end{array}$

9. *Questioning the teachings of my faith. $\quad \begin{array}{lllll}0 & 1 & 2 & 3\end{array}$ $\begin{array}{lllll}\text { How much distress does this cause you? } & 0 & 1 & 2 & 3\end{array}$

10. * Doubting the religious scriptures of my faith. $\quad \begin{array}{lllll}0 & 1 & 2 & 3\end{array}$ $\begin{array}{lllll}\text { How much distress does this cause you? } & 0 & 1 & 2 & 3\end{array}$

11. *Questioning core beliefs of my church $\quad \begin{array}{lllll}0 & 1 & 2 & 3\end{array}$ (synagogue or temple).

How much distress does this cause you? $\quad 0 \quad 0 \quad 1 \quad 2 \quad 3$

12. * Confused about my relationship with God. $\quad \begin{array}{lllll}0 & 1 & 2 & 3\end{array}$ $\begin{array}{lllll}\text { How much distress does this cause you? } & 0 & 1 & 2 & 3\end{array}$

13. *Frustrated with God. $\quad \begin{array}{lllll}0 & 1 & 2 & 3\end{array}$ How much distress does this cause you? $\quad \begin{array}{lllll}0 & 1 & 2 & 3\end{array}$

14. *Feeling secluded from God. $\quad \begin{array}{lllll}0 & 1 & 2 & 3\end{array}$ $\begin{array}{lllll}\text { How much distress does this cause you } & 0 & 1 & 2 & 3\end{array}$

15. * Feeling isolated from God. $\quad \begin{array}{lllll}0 & 1 & 2 & 3\end{array}$ $\begin{array}{lllll}\text { How much distress does this cause you? } & 0 & 1 & 2 & 3\end{array}$

16. *Wishing that God was here for me. $\quad \begin{array}{lllll}0 & 1 & 2 & 3\end{array}$ How much distress does this cause you? $\quad \begin{array}{lllll}0 & 1 & 2 & 3\end{array}$

17. * Shaky and nervous when thinking about God. $\quad \begin{array}{lllll}0 & 1 & 2 & 3\end{array}$ $\begin{array}{lllll}\text { How much distress does this cause you? } & 0 & 1 & 2 & 3\end{array}$

18. * Become tense when thinking about God. $\quad \begin{array}{lllll}0 & 1 & 2 & 3\end{array}$ $\begin{array}{lllll}\text { How much distress does this cause you? } & 0 & 1 & 2 & 3\end{array}$

Notes. * new items. 


\section{Appendix A-3: Struggle Characteristics}

\section{Finding Meaning}

1. I have found meaning in my spiritual struggle.

not at all

_ somewhat

quite a bit

a great deal

Notes: Finding meaning was assessed at time two only.

Impact of Event Severity

Regarding your spiritual struggle, please indicate how frequently you experience the following items using the scale below. If you do not experience an item, please circle “not at all".

1. I think about my spiritual struggle when

$$
\text { Not at All Rarely } \begin{gathered}
\text { Some- Often } \\
\text { times }
\end{gathered}
$$

\section{I don't mean to.}

2. I avoid letting myself get upset when I think about my spiritual struggle or am reminded of it.

3. I try to remove my spiritual struggle from memory.

4. I have trouble falling asleep or staying asleep because of pictures or thoughts about my spiritual struggle that come to mind.

5. I have waves of strong feelings about my spiritual struggle.

6. I have dreams about my spiritual struggle.

7. I stay away from reminders of my spiritual struggle.

8. I feel as if my spiritual struggle hasn't happened or isn't real.

$\begin{array}{llll}0 & 1 & 2 & 3\end{array}$

$\begin{array}{llll}0 & 1 & 2 & 3\end{array}$

$\begin{array}{llll}0 & 1 & 2 & 3\end{array}$

$\begin{array}{llll}0 & 1 & 2 & 3\end{array}$

$\begin{array}{llll}0 & 1 & 2 & 3\end{array}$

$\begin{array}{llll}0 & 1 & 2 & 3\end{array}$

$\begin{array}{llll}0 & 1 & 2 & 3\end{array}$

$\begin{array}{llll}0 & 1 & 2 & 3\end{array}$


9. I try not to talk about my spiritual struggle.

10. Pictures about my spiritual struggle pop into my mind.

11. Other things keep making me think about my spiritual struggle.

12. I am aware that I still have a lot of feelings about my spiritual struggle, but I don't deal with them.

13. I try not to think about my spiritual struggle.

14. Any reminder brings back feelings about my spiritual struggle.

15. My feelings about my spiritual struggle are kind of numb. $\begin{array}{llll}0 & 1 & 2 & 3\end{array}$

$\begin{array}{llll}0 & 1 & 2 & 3\end{array}$

$\begin{array}{llll}0 & 1 & 2 & 3\end{array}$

$\begin{array}{llll}0 & 1 & 2 & 3\end{array}$

$\begin{array}{llll}0 & 1 & 2 & 3\end{array}$

$\begin{array}{llll}0 & 1 & 2 & 3\end{array}$

$\begin{array}{llll}0 & 1 & 2 & 3\end{array}$


Appendix A-4: God Attachment Scale

Please indicate whether you agree or disagree with the following statements.

1. God seems impersonal to me.

Agree Disagree

12

2. God seems to have little or no interest in my personal problems.

12

3. God seems to have little or no interest in my personal affairs. $\quad \begin{array}{ll}2 & 2\end{array}$

4. I have a warm relationship with God. $\quad 1 \quad 2$

5. God knows when I need support. $\quad 1 \quad 2$

6. I feel that God is generally responsive to me. $\quad 1 \quad 2$

7. God sometimes seems responsive to my needs, but sometimes not.

12

8. God's reactions to me seem to be inconsistent.

12

9. God sometimes seems very warm and other times very cold to me.

12


Appendix A-5: Religious Integration

Using the scale below, please indicate how much you agree or disagree with the following statements.

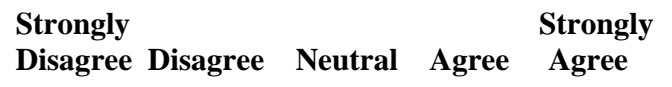

1. Religion is only one part of my life.

2

3

4

5

2. I wouldn't let my religion become more important to me than my friends or family.

3. *There's a time and place for religion, and a time and a place for other things in life.

1

4. *I don't really want to involve my religion in other parts of my life.

1

5. *I take my religion home with me after I leave church.

$\begin{array}{lllll}1 & 2 & 3 & 4 & 5\end{array}$

Note. $*=$ new items. 
Appendix A-6: The Multidimensional Scale of Perceived Social Support (MSPSS)

Using the scale below, please indicate how much you agree or disagree with the following statements.

1. There is a special person who is around $\begin{array}{lll}\text { Strongly } & \text { Strongly } \\ \text { Disagree Disagree Neutral Agree } & \text { Agree }\end{array}$ when I am in need.

$\begin{array}{lllll}1 & 2 & 3 & 4 & 5\end{array}$

2. There is a special person with whom I can share my joys and sorrows.

$\begin{array}{lllll}1 & 2 & 3 & 4 & 5\end{array}$

3. My family really tries to help me.

$\begin{array}{lllll}1 & 2 & 3 & 4 & 5\end{array}$

4. I get the emotional help and support I need from my family.

$\begin{array}{lllll}1 & 2 & 3 & 4 & 5\end{array}$

5. I have a special person who is a real source of comfort to me.

$\begin{array}{lllll}1 & 2 & 3 & 4 & 5\end{array}$

6. My friends really try to help me.

$\begin{array}{lllll}1 & 2 & 3 & 4 & 5\end{array}$

7. I can count on my friends when things go wrong.

$\begin{array}{lllll}1 & 2 & 3 & 4 & 5\end{array}$

8. I can talk about my problems with my family.

$\begin{array}{lllll}1 & 2 & 3 & 4 & 5\end{array}$

9. I have friends with whom I can share my joys and sorrows.

$\begin{array}{lllll}1 & 2 & 3 & 4 & 5\end{array}$

10. There is a special person in my life who cares about my feelings.

$\begin{array}{lllll}1 & 2 & 3 & 4 & 5\end{array}$

11. My family is willing to help me make decisions.

$\begin{array}{lllll}1 & 2 & 3 & 4 & 5\end{array}$

12. I can talk about my problems with my friends.

$\begin{array}{lllll}1 & 2 & 3 & 4 & 5\end{array}$


Appendix A-7: Religious Support Scale

Using the scale below, please indicate how much you agree or disagree with the following statements.

1. I can turn to others in my congregation for advice when I have problems.

$\begin{array}{lll}\text { Strongly } & \text { Strongly } \\ \text { Disagree Disagree Neutral Agree } & \text { Agree }\end{array}$

2. If something went wrong, my church leaders would give me assistance.

3. God gives me the sense that I belong.

4. Others in my congregation care about my life and situation.

$\begin{array}{lllll}1 & 2 & 3 & 4 & 5\end{array}$

$\begin{array}{lllll}1 & 2 & 3 & 4 & 5\end{array}$

$\begin{array}{lllll}1 & 2 & 3 & 4 & 5\end{array}$

5. I have worth in the eyes of my church leaders.

$\begin{array}{lllll}1 & 2 & 3 & 4 & 5\end{array}$

6. I feel appreciated by God.

$\begin{array}{lllll}1 & 2 & 3 & 4 & 5\end{array}$

7. I do not feel close to others in my congregation.

$\begin{array}{lllll}1 & 2 & 3 & 4 & 5\end{array}$

8. I can turn to church leadership for advice when I have problems.

$\begin{array}{lllll}1 & 2 & 3 & 4 & 5\end{array}$

9. If something went wrong, God would give me assistance.

$\begin{array}{lllll}1 & 2 & 3 & 4 & 5\end{array}$

10. Others in my congregation give me the sense that I belong.

$\begin{array}{lllll}1 & 2 & 3 & 4 & 5\end{array}$

11. My church leaders care about my life and situation.

$\begin{array}{lllll}1 & 2 & 3 & 4 & 5\end{array}$

12. I have worth in the eyes of God.

$\begin{array}{lllll}1 & 2 & 3 & 4 & 5\end{array}$

13. I feel appreciated by others in my congregation.

$\begin{array}{lllll}1 & 2 & 3 & 4 & 5\end{array}$

14. I do not feel close to my church leaders. $\quad \begin{array}{llllll}1 & 2 & 3 & 4 & 5\end{array}$

15. I can turn to God for advice when I have problems.

$\begin{array}{lllll}1 & 2 & 3 & 4 & 5\end{array}$


16. If something went wrong, others in my $\begin{array}{lllllll}\text { congregation would give me assistance. } & 1 & 2 & 3 & 4 & 5\end{array}$

17. My church leaders give me the sense that I belong.

$\begin{array}{lllll}1 & 2 & 3 & 4 & 5\end{array}$

18. God cares about my life and situation.

$\begin{array}{lllll}1 & 2 & 3 & 4 & 5\end{array}$

19. I have worth in the eyes of others in my congregation.

$\begin{array}{lllll}1 & 2 & 3 & 4 & 5\end{array}$

20. I feel appreciated by my church leaders. $\quad \begin{array}{llllll}1 & 2 & 3 & 4 & 5\end{array}$

21. I do not feel close to God. $\quad \begin{array}{llllll}1 & 2 & 3 & 4 & 5\end{array}$ 
Appendix A-8: Positive RCOPE

The following items ask what you did to cope with your spiritual struggle. Each item says something about a particular way of coping. We want to know to what extent you did what the items say. How much or how frequently. Don't answer on the basis of what worked or not-just whether or not you did it. Try to rate each item separately in your mind from the others. Make answers as true FOR YOU as you can. Circle the answer that best applies to you.

1. Tried to deal with the situation on my own without God's help.

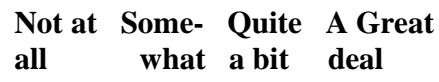

2. Worked together with God to relieve my worries. $\quad \begin{array}{lllll}0 & 1 & 2 & 3\end{array}$

$\begin{array}{lllll}\text { 3. Worked together with God as partners. } & 0 & 1 & 2 & 3\end{array}$

4. Saw my situation as part of God's plan. $\quad \begin{array}{lllll}0 & 1 & 2 & 3\end{array}$

5. Tried to deal with my feelings without God's help.

$\begin{array}{llll}0 & 1 & 2 & 3\end{array}$

6. Tried to make sense of the situation with God. $\quad \begin{array}{lllll}0 & 1 & 2 & 3\end{array}$

7. Sought comfort from God. $\quad \begin{array}{llll}0 & 1 & 2 & 3\end{array}$

8. Trusted that God would be by my side. $\quad \begin{array}{lllll}0 & 1 & 2 & 3\end{array}$

9. Made decisions about what to do without God's help.

$\begin{array}{llll}0 & 1 & 2 & 3\end{array}$

10. Trusted that God was with me.

$\begin{array}{llll}0 & 1 & 2 & 3\end{array}$

11. Depended on my own strength without support from God.

$\begin{array}{llll}0 & 1 & 2 & 3\end{array}$

12. Tried to see how the situation could be beneficial spiritually.

$\begin{array}{llll}0 & 1 & 2 & 3\end{array}$

13. Tried to make sense of the situation without relying on God.

$\begin{array}{llll}0 & 1 & 2 & 3\end{array}$

14. Looked to God for strength, support, and guidance.

$\begin{array}{llll}0 & 1 & 2 & 3\end{array}$

15. Thought that the event might bring me closer to God.

$\begin{array}{llll}0 & 1 & 2 & 3\end{array}$


16. Tried to find a lesson from God in the event. $\quad \begin{array}{lllll}0 & 1 & 2 & 3\end{array}$

17. Tried to see how God might be trying to strengthen me in this situation.

$\begin{array}{llll}0 & 1 & 2 & 3\end{array}$

18. Asked God to help me be more forgiving.

$\begin{array}{llll}0 & 1 & 2 & 3\end{array}$

19. Confessed my sins.

$\begin{array}{llll}0 & 1 & 2 & 3\end{array}$

20. Tried to be less sinful.

$\begin{array}{llll}0 & 1 & 2 & 3\end{array}$

21. Sought help from God in letting go of my anger. $\begin{array}{lllll}0 & 1 & 2 & 3\end{array}$

22. Thought about how my life is part of a larger spiritual force.

$\begin{array}{llll}0 & 1 & 2 & 3\end{array}$

23. Asked forgiveness for my sins.

$\begin{array}{llll}0 & 1 & 2 & 3\end{array}$

24. Searched for forgiveness from God.

$\begin{array}{llll}0 & 1 & 2 & 3\end{array}$

25. Sought spiritual help to give up my resentments. $\begin{array}{lllll}0 & 1 & 2 & 3\end{array}$

26. Sought God's help in trying to forgive others. $\quad \begin{array}{llllll}0 & 1 & 2 & 3\end{array}$

27. Tried to experience a stronger feeling of spirituality.

$\begin{array}{llll}0 & 1 & 2 & 3\end{array}$

28. Tried to build a strong relationship with a higher power.

$\begin{array}{llll}0 & 1 & 2 & 3\end{array}$

29. Asked God to help me be less sinful. $\quad \begin{array}{llll}0 & 1 & 2 & 3\end{array}$

30. Asked God to help me overcome my bitterness. $\begin{array}{llllll}0 & 1 & 2 & 3\end{array}$ 


\section{APPENDIX B. OUTCOME MEASURES}

B-1: $\quad$ Struggle Related Outcome

B-2: $\quad$ Posttraumatic Growth Inventory

B-3: $\quad$ Satisfaction with Life Scale

B-4: $\quad$ Spiritual Growth

B-5: $\quad$ Spiritual Decline 
Appendix B-1: Struggle Related Outcomes

1. I feel that my spiritual struggle has...*

___ been completely resolved.

been partially resolved.

n not changed.

become worse.

2. As a result of my spiritual struggle, I have... * grown. declined. both grown and declined. neither grown nor declined.

Please explain your response to question 2:

Notes. * Only assessed at time two 
Appendix B-2: Posttraumatic Growth Inventory

Indicate for each of the statements below the degree to which this change occurred in your life as a result of your spiritual struggle, using the following scale:

\section{As a result of my spiritual struggle...}

I did not experience this change.

\section{0}

I experienced this change to a very small degree. 1

I experienced this change to a small degree. $\quad 2$

I experienced this change to a moderate degree. 3

I experienced this change to a great degree. 4

I experienced this change to a very great degree. 5

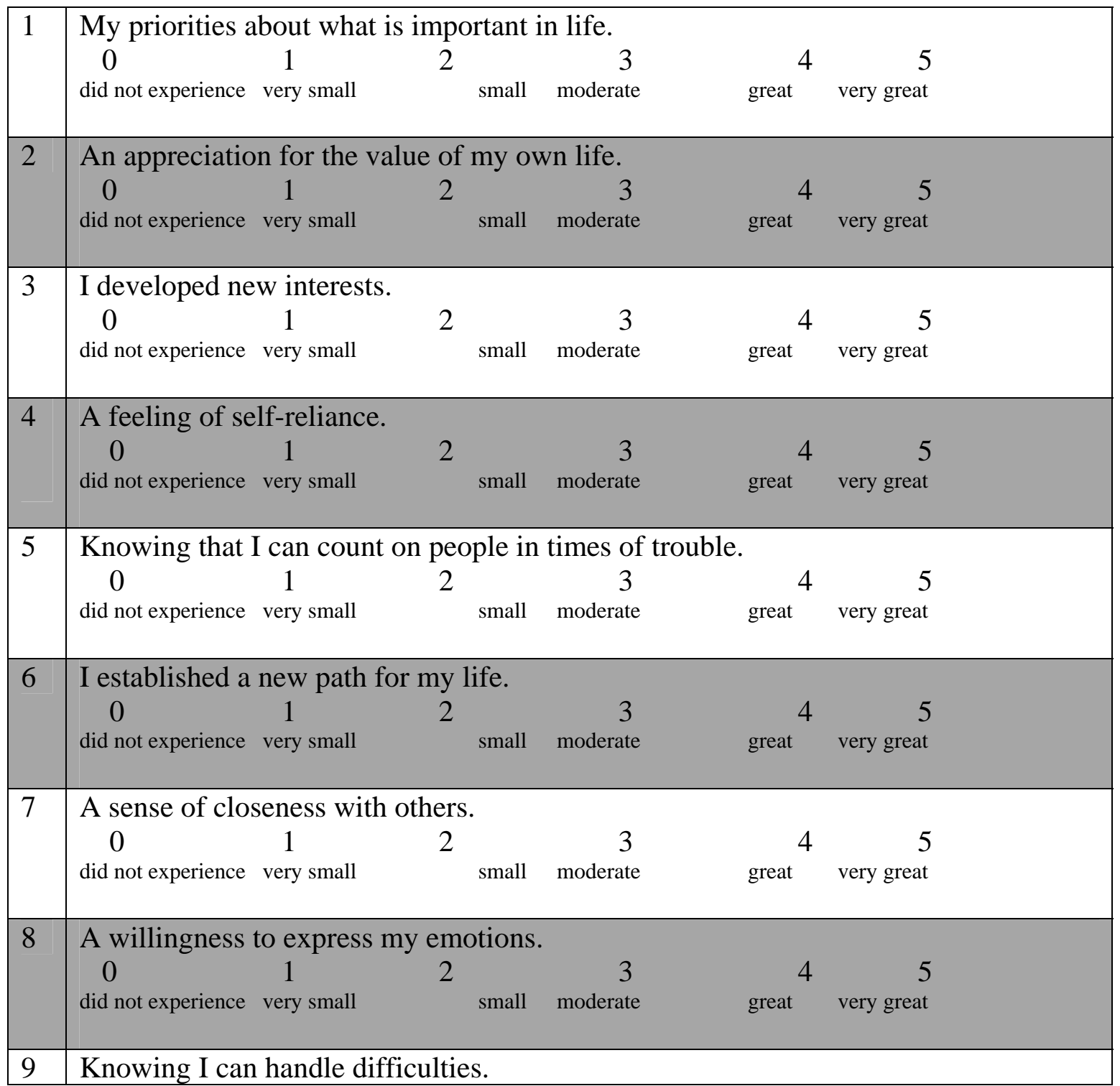




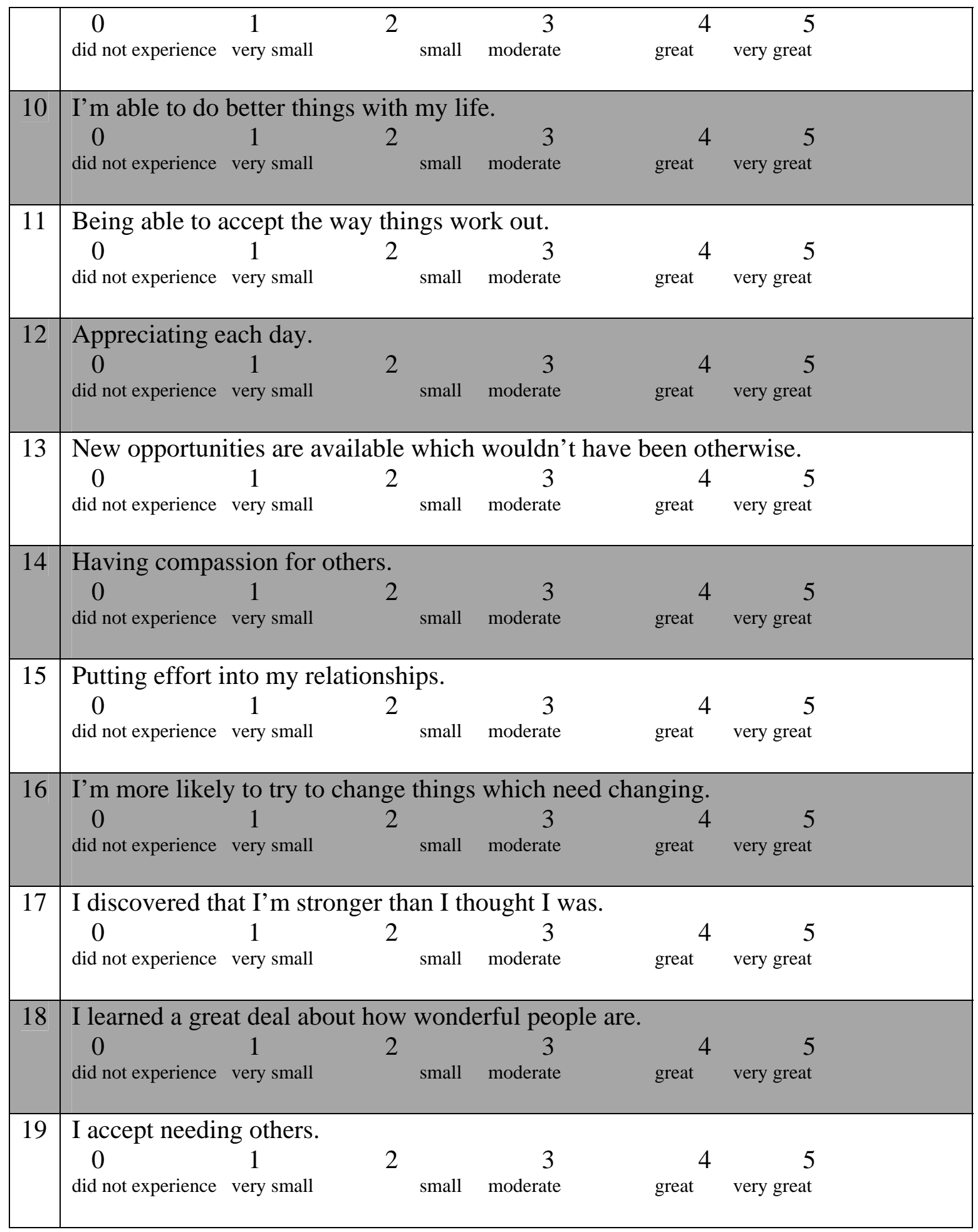


Appendix B-3: Satisfaction with Life Scale

Below are statements with which you may agree or disagree. Using the 1-7 scale below, indicate your agreement with each item by placing the appropriate number on the line preceding that item. Please be open and honest in your responding. The 7-point scale is as follows:

$$
\begin{aligned}
& 1=\text { strongly disagree } \\
& 2=\text { disagree } \\
& 3=\text { slightly disagree } \\
& 4=\text { neither agree nor disagree } \\
& 5=\text { slightly agree } \\
& 6=\text { agree } \\
& 7=\text { strongly agree }
\end{aligned}
$$

1) In most ways my life is close to ideal.

2) The conditions of my life are excellent.

3) I am satisfied with my life.

4) So far I have gotten the important things I want in life.

5) If I could live my life over, I would change almost nothing. 
Appendix B-4: Spiritual Growth

Below are statements with which you may agree or disagree. Using the 1-7 scale below, indicate your agreement with each item by placing the appropriate number on the line preceding that item. Please be open and honest in your responding. The 7-point scale is as follows:

$$
\begin{aligned}
& 1=\text { strongly disagree } \\
& 2=\text { disagree } \\
& 3=\text { slightly disagree } \\
& 4=\text { neither agree nor disagree } \\
& 5=\text { slightly agree } \\
& 6=\text { agree } \\
& 7=\text { strongly agree }
\end{aligned}
$$

1) Spiritually, I am like a new person.

2) I have grown spiritually.

3) My experience of God has changed in a positive way.

4) I have grown closer to God.

5) Spirituality has become more important to me. 
Appendix B-5: Spiritual Decline

Below are statements with which you may agree or disagree. Using the 1-7 scale below, indicate your agreement with each item by placing the appropriate number on the line preceding that item. Please be open and honest in your responding. The 7-point scale is as follows:

$$
\begin{aligned}
& 1=\text { strongly disagree } \\
& 2=\text { disagree } \\
& 3=\text { slightly disagree } \\
& 4=\text { neither agree nor disagree } \\
& 5=\text { slightly agree } \\
& 6=\text { agree } \\
& 7=\text { strongly agree }
\end{aligned}
$$

1) I have grown more distant from God.

2) Spirituality seems less important to me now.

3) I no longer consider myself a spiritual person.

4) In some ways I have shut down spiritually.

5) My experience of God has changed in a negative way. 